\title{
Environmental Stressors and Lipid Production in Dunaliella spp. II. Nutrients, pH, and light under optimal or low salinity
}

\author{
$\underline{\text { Stephanie M. Mixson Byrd }}{ }^{1,2} *$ and JoAnn M. Burkholder ${ }^{1}$
}

\begin{abstract}
Fourteen strains within four species of the halophytic microalgal genus, Dunaliella were rapidly screened for cellular lipid content during senescence using an adapted Nile Red technique. Four promising strains that exhibited both rapid population growth and high lipid content, including three strains of Dunaliella tertiolecta and one strain of D. viridis, were selected to attempt to enhance lipid production as total fatty acids (FAs) in bench-scale cultures ( 0.5 to $3.5 \mathrm{~L}$ ) under environmental stressors including nutrient limitation or deprivation of inorganic nitrogen (nitrate, $\mathrm{N}$ ) and/or phosphorus (P), $\mathrm{pH}$ stress (control - early senescent cultures, versus $\mathrm{pH} 10$ or $\mathrm{pH}$ 7), a 12-hr : 12-hr light:dark (L:D) photoperiod versus continuous light, and enrichment versus no enrichment with carbon dioxide $\left( \pm\right.$ 4-hr pulse daily of bubbling with $\left.\mathrm{CO}_{2}\right)$. These strains were also tested in mass culture ( 150 to $175 \mathrm{~L})$ to test feasibility of scale-up. All but one strain had minimal lipid production during active growth, and increased lipid production under senescence. The unique strain Dunaliella viridis UTEX ZZ1150 produced high amounts of total FAs during
\end{abstract}


25 active growth as well as senescence, whether in a 12:12 L:D photoperiod or under continuous

26 light. High pH x low salinity, low pH (7), and continuous light + pulsed $\mathrm{CO}_{2}$ yielded the

27 maximum total FA content of $56 \%, 43 \%$, and $42 \%$ (dry weight basis), respectively, in

28 comparison to controls ( $\sim 10$ to $25 \%$ total FAs). Under continuous light \pm pulsed $\mathrm{CO}_{2}$, cells likely

29 incorporated the excess carbon as FAs and other products. Low N and/or P under a 12:12 L:D

30 photoperiod or continuous light, and a 12:12 L:D with pulsed $\mathrm{CO}_{2}$, did not significantly enhance

31 total FA production. High intraspecific and interspecific variation in growth and lipid production

32 was found in Dunaliella in response to each environmental stressor, suggesting fundamental

33 metabolic differences.

34 Keywords: Dunaliella, $\mathrm{CO}_{2}$, continuous light, lipids, nitrogen, $\mathrm{pH}$, phosphorus, photoperiod

\section{Introduction ${ }^{1}$}

Microalgae have high surface area-to-volume ratios, facilitating rapid responses to

environmental stressors (Becker, 1994; Rodolfi et al., 2009; Sharma et al., 2012). They can

39 rapidly alter their lipid metabolism in terms of total content and composition (Roessler 1990) in

40 response to factors such as temperature (Lynch and Thompson, 1982; Thompson et al., 1992),

41 light (Peeler and Thompson, 1990; Gordillo et al., 1998), pH (Gardner et al., 2012), and salinity

42 (Xu and Beardall, 1997; Azachi et al., 2002; Takagi et al., 2006). Dunaliella spp.

43 (Chlorophyceae), as promising candidates for sustainable biofuel production, have been studied 44 in detail with regard to salinity stress and its effect on increasing total fatty acids (FAs) (Azachi 45 et al., 2002; Oren, 2005; Takagi et al., 2006; Ben-Amotz et al., 2009; Mixson et al., submitted).

\footnotetext{
${ }^{1}$ FAs, fatty acids; FID, flame ionization detector; GC, gas chromatography; NR, Nile Red; TAGs, triacylglycerides
} 
Lipids generally are considered to provide a storage function that helps to enable the cell to survive adverse environmental conditions or stressors (Fields et al., 2014). In Part I of this work

(companion paper, Mixson et al. submitted), we focused in detail on effects of salinity stress alone. Here we investigated the effects of various abiotic stressors on total FA production in four strains of Dunaliella within two species. The environmental stressors included low nutrients or nutrient deprivation, low and high $\mathrm{pH}$ stress, and two different light regimes with/without pulsed $\mathrm{CO}_{2}$ under optimal or low salinity.

Deprivation of macronutrients such as nitrogen and phosphorus can significantly enhance lipid accumulation, depending on the species, strain, and other environmental conditions (Fields et al. 2014). Lack of nitrogen limits protein synthesis which is needed for most cellular functions including photosynthesis and cell division, and cells compensate by using alternative metabolic pathways for inorganic carbon fixation such as fatty acid synthesis (Msanne et al., 2012). When cell growth and division are impeded by lack of nutrients, the supply of the major electron acceptor for photosynthesis, $\mathrm{NADP}^{+}$, can be depleted. FA synthesis consumes NADPH and ATP, and maintains the NADP ${ }^{+}$pool (Brown et al., 2009; Sharma et al., 2012; Fields et al., 2014). Inorganic nitrogen $(\mathrm{N})$ limitation has been found to promote an increase in neutral lipids

64 the presence of $\mathrm{N}$ deficiency partly because $\mathrm{N}$ is not a component of storage and membrane 65 lipids. Shifrin and Chisholm (1981) completed an in-depth study on the effects of N limitation on 66 total lipids within species of chlorophytes, and found that Dunaliella spp. did not increase neutral 67 lipids. In general, when phosphorus (P) becomes deficient, protein, chlorophyll $a$, RNA, and 68 DNA tend to decrease while carbohydrate storage products increase (Kaplan et al., 1986). Arias- 
69 Forero et al. (2013) reported a N-limiting threshold, as a N:P ratio of 14:1 by weight, for

70 stimulation and accumulation of triglycerides; on the other hand, Song et al. (2016) found that a

71 strain of Dunaliella tertiolecta had maximal lipid content at an atomic N:P ratio of 4:1 when

72 nitrate or urea was the nitrogen source. P limitation in microalgal chlorophytes has decreased

73 lipid content in some taxa (e.g., Nannochloris, Tetraselmis) and increased lipid content in others

74 (e.g., Chlorella kessleri) (El-Sheek and Rady, 1995; Widjaja et al., 2009). The influence of P

75 limitation on lipid production in Dunaliella is poorly known, as are the effects of combined N+P 76 limitation.

Use of $\mathrm{pH}$ stress to induce microalgal accumulation of lipids has been applied to other chlorophytes (Guckert and Cooksey, 1990; Gardner et al., 2011; Santos et al., 2012). As microalgae consume carbon, cell division occurs and the extracellular $\mathrm{pH}$ in the medium increases (Sager and Granick, 1953; Azov, 1982; Guckert and Cooksey, 1990). Species respond differently physiologically and biologically to external $\mathrm{pH}$, and there can also be high intraspecific variation. In a recent study of the interaction between high $\mathrm{pH}$ and $\mathrm{N}$ limitation on triacylglyceride (TAG) production, two chlorophytes accumulated TAGs in response to high $\mathrm{pH}$ (> 9) $+\mathrm{N}$ deprivation, as indicated by Nile Red fluorescence (Gardner et al., 2011). The $\mathrm{pH}$ experiments conducted here additionally considered rapid, short-term, and long-term responses, briefly defined here as the time frames $30 \mathrm{sec}$ to $\leq 5 \mathrm{~min}$, up to $2-3 \mathrm{hr}$, and $\geq 24 \mathrm{hr}$, respectively (also see Mixson et al. submitted). The nutrient limitation variable indicated by Gardner et al. (2011) was eliminated in those experiments, so that any increase in total FAs was in response to $\mathrm{pH}$ stress.

Carbon (C) accounts for almost 50\% of the overall dry weight of microalgal biomass (Becker 1994) and, of course, carbon is required for lipid biosynthesis (Palmqvist et al., 1988; 
92 Spalding, 2008). Microalgae synthesize various intracellular C compounds from DIC uptake

93 during the light period (Kaplan et al., 1986; Carvalho and Malcata, 2004). Algae commonly are

94 cultured in a 12:12 (light, 12-14 hr; dark, 10-12 hr) light:dark (L:D) photoperiod. Although most 95 algae grow poorly or cease growth in continuous light (Carvalho and Malcata 2004; Lorenz et 96 al., 2005), continuous light has promoted higher biomass production than L:D photoperiods for 97 algae such as the rhodophyte Porphyridium (Porphyridiophyceae; Yongmanitchai and Ward, 98 1992) and the chlorophyte Dunaliella bardawil (Ben-Amotz and Avron, 1983). This information 99 was extended by examining the response of two other Dunaliella strains to increased pulses of $100 \mathrm{CO}_{2}$ under continuous light. In addition, environmental stressors that appeared to be especially 101 promising in enhancing Dunaliella lipid production in preliminary trials were tested in both 102 bench scale and mass culture experiments. The difference in experimental scale was imposed 103 because of the "container effects" shown for various algae (Ben-Amotz and Avron, 1989; 104 García-González et al., 2003), and in recognition of the importance of scale-up feasibility in 105 harnessing algae for biofuel production.

\section{Materials and Methods}

\subsection{Strains, Stock Cultures, and Cell Counts - Fourteen strains of Dunaliella were visually} screened for visually high neutral lipid content with a fluorescent Nile Red dye technique specially adapted for use with Dunaliella spp. (Mixson, 2013). Of these, five initially were selected for use in the experiments. These strains were obtained from the Culture Collection of Algae and Protozoa (CCAP) and the Culture Collection of Algae at the University of Texas at Austin (UTEX). They included D. tertiolecta strains CCAP 19/9 $\left(120 \pm 6 \mu \mathrm{m}^{3}\right.$, mean \pm 1 standard deviation [SD], $\mathrm{n}=30$ cells $),$ CCAP 19/24 $\left(132 \pm 6 \mu \mathrm{m}^{3}\right)$, UTEX $999\left(163 \pm 9 \mu \mathrm{m}^{3}\right)$, 
and UTEX $1000\left(168 \pm 8 \mu \mathrm{m}^{3}\right)$, and $D$. viridis UTEX ZZ1150 $\left(74 \pm 5 \mu \mathrm{m}^{3}\right)$ (Table 1; and see

117 Mixson et al. submitted). The strains were purified using a combination of differential

118 centrifugation and flow cytometry (Beckman Coulter® EPICS Altra, NCSU) to remove bacterial contamination (Guillard, 2005; Kawachi and Noël, 2005), as described in Mixson (2013) and Mixson et al. (submitted). Culture cell densities and cell production were assessed from subsamples preserved in acidic Lugol's solution (1\% final concentration; Vollenweider et al., 1974), and quantified within 1-2 days using Palmer-Maloney chambers (Wetzel and Likens, 2010) under light microscopy at 200x using an Olympus BH-2 light microscope.

ITS2 sequence data for each of the five strains indicated that they fell within two distinct species (clades) instead of the expected three. Three of the five strains tested in these experiments additionally had been labeled incorrectly (Chapter 2) (Table 4.1). Additionally, “Dunaliella salina strain UTEX 1644" was found to have been a D. viridis contaminant of that culture (Mixson et al., 2014). The strain, of unknown origin, proved to be unique in major features including cell size, population growth as cell production, sustained growth in continuous light, and high lipid production throughout the cell cycle. Based on that information, the strain was not simply a contaminant from the other Dunaliella cultures. Strain UTEX 1644 was ordered in 2013 from the UTEX collection by another laboratory, and was confirmed as $D$. salina rather than this unique strain. Thus, the unique strain sent to us by the UTEX collection in 2009 was a contaminant that can no longer be obtained under the number, UTEX 1644. As the research revealed that this strain is of special interest for its growth and lipid production, this strain was deposited at the UTEX collection (D. viridis strain UTEX ZZ1150). The other strains are referred to here by the species name indicated from the ITS2 sequence data (D. tertiolecta), along with the original strain numbers. The strains included D. tertiolecta CCAP 19/9 (120 46 
$139 \mu \mathrm{m}^{3}$, mean $\pm 1 \mathrm{SD}, \mathrm{n}=30$ cells), CCAP 19/24 $\left(132 \pm 6 \mu \mathrm{m}^{3}\right)$, UTEX $999\left(163 \pm 9 \mu \mathrm{m}^{3}\right)$, and

140 UTEX $1000\left(168 \pm 8 \mu \mathrm{m}^{3}\right)$; and D. viridis UTEX ZZ1150 $\left(74 \pm 5 \mu \mathrm{m}^{3}\right)$ (Mixson et al.,

141 submitted; Table 1).

Preliminary work indicated that the Dunaliella strains grew well in Erdschreiber's (Føyn 1934), Artificial Seawater (ASW, made using f/2-Si nutrients; Guillard, 1975; Tompkins et al., 1995), and L1-Si medium (Guillard and Hargraves, 1993), at salinity 30 or 60 depending on the strain. Erdschreiber's and ASW media contained soil water with undefined constituents, and 146 nutrient components of f/2-Si were similar to those in L1-Si. Therefore L1-Si was selected for 147 use in this study. Once growth was established for strains in the source media (Table 1; salinity 14830 or 60), each culture was transferred into a series of increasing proportions of L1-Si and the 149 source medium (after Lorenz et al., 2005) until the cells finally were acclimated to $100 \%$ L1-Si 150 medium. Cell production for each strain was compared in its source medium versus L1-Si 151 medium. All strains attained comparable or higher maximum cell production in L1-Si medium 152 (Mixson et al. submitted). In a second series of transfers, cultures were adjusted by salinity \pm 5 153 to 10 (for each adjustment) using $\mathrm{NaCl}$ (YSI 3200 Conductivity Instrument, Yellow Springs, 154 Ohio, U.S.A.), and tested for population growth rate (as cell production) to determine the optimal 155 salinity for each strain (Mixson et al. submitted). An analogous approach was applied to identify 156 the optimum $\mathrm{pH}$ for each strain, using incremental changes of $0.1 \mathrm{pH}$ unit (PerpHecT $\operatorname{LogR}$ 157 meter 350, Boston, Massachusetts, U.S.A.) from an initial pH of 7.5 to 8.5. Accordingly, three 158 strains (D. tertiolecta CCAP 19/9, UTEX 999, and UTEX 1000) were grown at an optimal 159 salinity of 30 and optimal $\mathrm{pH}$ of 8.0-8.4 for cell production; the other two strains (D. tertiolecta 160 CCAP 19/24 and D. viridis UTEX ZZ1150) were grown at their optimum salinity of 60 and 161 optimal $\mathrm{pH}$ of 8.0 to 8.4. Stock culture for each strain was grown at $23^{\circ} \mathrm{C}$ and $\sim 180 \mu \mathrm{E} / \mathrm{m}^{2} / \mathrm{sec}$ 
162 (light source, ProLume ${ }^{\circledR}$ compact fluorescent bulbs) under a 12-hr : 12-hr light : dark (LD) 163 photoperiod.

164 To check species identifications, strains were purified using a combination of differential 165 centrifugation and flow cytometry (Beckman Coulter® EPICS Altra, Hialeah, Florida, U.S.A.) to 166 remove bacterial contaminants (Guillard, 2005; Kawachi and Noël, 2005; Mixson et al., 167 submitted). Cultures were plated on 1\% Agar M (Sigma Aldrich®, St. Louis, Missouri, U.S.A.)

2.2 Mass Cultures - The mass cultures consisted of series of growth tubes, each $1.21 \mathrm{~m}$ height $\mathrm{x}$ $30 \mathrm{~cm}$ diameter, made of lightweight $0.1-\mathrm{cm}$ polymer fiberglass which provided $\sim 90 \%$

transparency. Each tube held a maximum of $~ 175$ L. Unless otherwise specified, cultures were grown under a 12:12 L:D photoperiod. The light source consisted of fluorescent light banks (Standard Utilitech, $123.2 \mathrm{~cm}$ lights) that provided $\sim 160$ to $180 \mu \mathrm{E} / \mathrm{m}^{2} / \mathrm{sec}$ for each tube.

The temperature for these experiments was maintained at $23 \pm 1^{\circ} \mathrm{C}$. Tubes were sampled daily between 0800 and $0900 \mathrm{hr}$ for temperature, $\mathrm{pH}$ (Oakton Waterproof $\mathrm{pH}$ Testr 30 Pocket $\mathrm{pH}$

Tester, Oakton Instruments, Vernon Hills, Illinois, U.S.A.), and cell counts (see Section 2.1). In preparation for mass culturing, tubes were filled with $\sim 150 \mathrm{~L}$ deionized water adjusted to the desired salinity (30 or 60; Hydrolab MiniSonde 4, Hach Company, Loveland, Colorado, U.S.A.) and pH (8.3-8.4) with Coralife ${ }^{\circledR}$ salts (CL; Franklin, Wisconsin, U.S.A.) + 19.35 mL each of ProLine ${ }^{\circledR}$ A and B nutrient mixtures (F/2 following Guillard, 1975; Aquatic Eco-Systems, Apopka, Florida, U.S.A.). Stock culture was grown by inoculating 3 L volume (salinity 30 or 60 , adjusted with CL + L1-Si nutrients) with $300 \mathrm{~mL}$ of culture (i.e., a 10\% 
inoculum) under the growth conditions described above. Once the stock reached late exponential growth as determined by cell counts, it was added to a freshly prepared mass culture tube $(\sim 3.5 \mathrm{~L}$ stock culture in $\sim 150 \mathrm{~L}$ prepared medium) and grown as inoculum for mass culture experiments. When this inoculum tube reached late exponential growth (typically within 7-10 days), $15 \mathrm{~L}$ were dispensed into each freshly prepared mass culture tube that was filled with $\sim 150 \mathrm{~L}$ culture medium as described above. Thus, the maximum volume for a given tube was $\sim 165 \mathrm{~L}$ including culture. The total number of tubes prepared varied by experiment. Cultures of Dunaliella were grown to a density of $10^{6}$ (rarely, $10^{7}$ ) cells/mL within $7-10$ days depending on the strain and the experimental conditions.

\subsection{Low Nitrogen and/or Phosphorus - In bench-scale preliminary trials, D. viridis UTEX}

ZZ1150 and D. tertiolecta UTEX 1000 were grown under low $\mathrm{N}$ or $\mathrm{N}$ deprivation ( $\mathrm{N}$ as nitrate, $\mathrm{NO}_{3}{ }^{-} \mathrm{N}$, added as $10 \%$ or $0 \%$ of replete conditions, respectively) and/or low $\mathrm{P}$ or $\mathrm{P}$ deprivation ( $\mathrm{P}$ as $\mathrm{PO}_{4}^{-3} \mathrm{P}$, added as $10 \%$ or $0 \%$ of nutrient-replete conditions, respectively). Nutrient deprivation was included to enable comparison of these results to other studies that used nutrientfree medium in an attempt to enhance total lipid production in Dunaliella (e.g. Shifrin and Chisholm, 1981; Davidi et al., 2012). Preliminary trials were also conducted using $\mathrm{NH}_{4}{ }^{+}$as the $\mathrm{N}$ source, but $\mathrm{NH}_{4}{ }^{+} \mathrm{N}$ resulted in poor growth, so the experiments included nitrate as the inorganic $\mathrm{N}$ source.

In the preliminary trials, the two strains attained maximal lipid content of $40-60 \%$ as total fatty acids (FAs). In preliminary trials, D. tertiolecta UTEX 1000 attained maximal biomass of $73.5 \mathrm{~g}$ fresh weight (fr wt) per mass culture tube on day 5 (at optimal salinity 30 ), and maximal lipid production of $29.4 \mathrm{~g}$ fr wt per tube on day 11. By comparison, D. viridis UTEX ZZ1150 maximal biomass of $42.7 \mathrm{~g}$ fr wt per tube occurred on day 7 (at optimal salinity 60), and 
maximal lipid production was $36.4 \mathrm{~g}$ fr wt per tube on day 9. Shortly after the preliminary trials, 211 however, $D$. tertiolecta UTEX 1000 inexplicably lost its ability to produce significant amounts

212 of neutral lipids. Thus, it was eliminated from further considered in the environmental stressor 213 experiments.

\subsection{Long-Term pH Stress - Strain D. viridis UTEX ZZ1150 was grown in mass culture as} described above. Replicate controls $(n=3)$ were transferred from salinity 60 to 60 or from salinity 60 to 30 ( $\mathrm{n}=3$ for each salinity) and were maintained at $\mathrm{pH} 8.3-8.4$ after addition of the nutrient mixture and the Dunaliella culture inoculum. Likewise, replicate treatment cultures in salinity 60 or salinity $30(n=3$ for each salinity) were adjusted to $\mathrm{pH} 10$ using $6 \mathrm{~N} \mathrm{NaOH}$. 

235 readings. Subsamples $(\sim 500 \mathrm{~mL})$ were centrifuged at $\sim 3$-day intervals and immediately frozen at $236-80^{\circ} \mathrm{C}$ until total FA analysis. Controls were compared to treated (high $\mathrm{pH}$ ) cultures at each 237 salinity level, allowing for determination of the effect of $\mathrm{pH}$ alone on FA production.

238

239

Replicates were grown until senescence ( 21 days) as determined by cell counts and $\mathrm{pH}$

2.5 Short-Term $\mathrm{pH}$ Stress - In preliminary work, Dunaliella growth as cell production in response to $\mathrm{pH}$ was tested across a $\mathrm{pH}$ range of 2 to 12 with four strains, including $D$. tertiolecta CCAP 19/9, CCAP 19/24, and UTEX 999, and D. viridis UTEX ZZ1150. Low or no growth as cell production was tracked for cultures grown at an initial $\mathrm{pH}$ of $2,4,6$, or 12 . From those observations, low and high $\mathrm{pH}$ treatments were selected at $\mathrm{pH} 7$ and $\mathrm{pH} 10$, respectively. Each strain was grown in replicate cultures $(n=3)$ at $\sim 3.5$ L volume under the conditions described above. Cells were quantified from preserved subsamples above until cultures reached early senescence.

Each replicate culture was evenly distributed into seven sterile 50-mL centrifuge tubes by centrifuging (3,000 RPM, $10 \mathrm{~min}) \sim 500 \mathrm{~mL}$ culture and adding the pellet to a tube; thus, the final pellet in each tube was concentrated from $\sim 500 \mathrm{~mL}$ of culture. Pellets were re-suspended into $50 \mathrm{~mL}$ of medium at either low $\mathrm{pH}$ (7) or high $\mathrm{pH}$ (10). After re-suspension, replicates were sampled for cell counts and semi-quantitative assessment of lipid content via fluorescence microscopy after Nile Red (NR) staining (Mixson et al. submitted), before (at the control pH) and at $30 \mathrm{sec}, 5 \mathrm{~min}, 30 \mathrm{~min}, 1 \mathrm{hr}, 2 \mathrm{hr}$, and $24 \mathrm{hr}$ after exposure to the altered $\mathrm{pH}$. NR (9diethylamino-5H-benzo( $\alpha$ )phenoxazine-5-one (Sigma-Aldrich) is used to reveal the presence of neutral lipid droplets (Pinkart et al., 1998; Yao et al., 2016). In the method used here, $10 \mu \mathrm{L}$ of NR $(0.625 \mu \mathrm{g} / \mathrm{mL}$ dissolved in $100 \% \mathrm{MeOH})$ was added to slides (slightly heated on a hotplate set to low) containing 2 drops of culture with cells that had been immobilized on $1.3 \%$ Type V 
agarose (Sigma Aldrich). Cells of each strain/treatment were photographed at 600x using an Olympus AX 70 microscope (excitation, $488 \mathrm{~nm}$; emission, 545-655 nm) and an Olympus DP70 camera. Samples were centrifuged (3,000 RPM, $10 \mathrm{~min})$ and immediately frozen at $-80^{\circ} \mathrm{C}$ until total FA analysis.

2.6 $\underline{\mathrm{CO}}_{2} \underline{x}$ Light Regime - The strain Dunaliella viridis UTEX ZZ1150 was tested in benchscale preliminary trials ( $\sim 500-\mathrm{mL}$ cultures $)$ and was shown to produce neutral lipids under both a 12:12 L:D photoperiod and CL based on fluorescence microscopy with NR-stained cells as described above. Effects of continuous versus pulsed bubbling of $\mathrm{CO}_{2}$ were also tested. Continuous bubbling resulted in $\mathrm{pH}$ readings below neutral $(\sim 6.5-7.0)$, which was detrimental to cell growth. Therefore, $\mathrm{CO}_{2}$ was bubbled for a daily pulse $4 \mathrm{hr}$ between 0010 and $1400 \mathrm{hr}$ when highest photosynthetic activity was expected.

Stock culture of $D$. viridis UTEX ZZ1150 was grown at salinity 30 and other growth conditions described above at $\sim 3.5 \mathrm{~L}$ volume, and was added to a freshly prepared mass culture tube (mass culture stock A; Section 2.2). After one week the culture was in exponential growth phase $\left(\sim 8.50 \times 10^{5}\right.$ cells $\left./ \mathrm{mL}\right)$. Eight freshly prepared tubes were each inoculated with $15 \mathrm{~L}$ of mass culture stock A. All tubes were sampled daily between 0800 and 0900 for temperature, $\mathrm{pH}$, 275 and cell counts. When the mass cultures had reached mid-exponential growth phase (usually on 276 day 6), $\mathrm{CO}_{2}$ was bubbled for $4 \mathrm{hr}$ (at $1000-1400 \mathrm{hr}$ ) daily for the remainder of the experiment 277 in 4 of the 8 tubes (12:12 L:D). The remaining tubes served as controls and were sampled 278 following the same regime as in days 1-5.

A second experiment in a separate set of mass culture tubes was set up similarly; then continuous light (CL) was imposed for all eight tubes from day 6 through the remainder of the 
experiment. Four tubes also received $4 \mathrm{hr}$ of bubbling $\mathrm{CO}_{2}$ (during $1000-1400 \mathrm{hr}$ ) beginning at day 6.

Control tubes did not receive $\mathrm{CO}_{2}$ enrichment in either experiment. For both experiments (12:12 L:D \pm pulsed $\mathrm{CO}_{2}$, and $\mathrm{CL} \pm$ pulsed $\left.\mathrm{CO}_{2}\right), \mathrm{a} \sim 500 \mathrm{~mL}$ subsample was taken between 0800 - $0900 \mathrm{hr}$ and centrifuged (3,000 RPM, $10 \mathrm{~min})$ on days 6, 9, and 12, representing midexponential, late exponential, and early senescence growth phases, respectively. Pellets were stored at $-80^{\circ} \mathrm{C}$ until FA analysis.

2.7 Total FAs - Direct transesterification (DT; Griffiths et al., 2010; Mixson et al., submitted) was performed to convert saponifiable lipids to FA methyl esters (hereafter, total FAs), which were then directly quantified using gas chromatography (GC) with a flame ionization detector (FID). In this process, a combination of acidic and basic transesterification catalysts was used. Briefly, 0.5 M methanolic $\mathrm{KOH}$ was added to each sample; samples were then homogenized and heated to $85^{\circ} \mathrm{C}$. Then, $\mathrm{BF}_{3}(14 \%$ in $\mathrm{MeOH})$ was added and samples were re-heated to $85^{\circ} \mathrm{C}$. Equal volumes of water and hexane were added and the samples were allowed to separate into layers. The hexane layer, containing neutral lipids, was removed and analyzed with a GC HP5890 series II GC equipped with a FID (Hewlett Packard, refurbished by Primera Scientific LLC, Princeton, New Jersey, U.S.A.) and a 7673A autosampler (Alpha Omega Technologies, Inc., refurbished by Primera Scientific LLC). Separation was achieved in an Rtx-2330 capillary column. The temperature was programmed for an initial 3 min at $60^{\circ} \mathrm{C}$, increasing at a rate of $4^{\circ} \mathrm{C} \mathrm{min}-1$ to a final temperature of $230^{\circ} \mathrm{C}$. Both injector and detector temperatures were set at $265^{\circ} \mathrm{C}$, and injections were performed under the splitless mode. Data acquisition and analysis were completed using GC Chemstation Rev. A.08.03 (847) software. Calculations for total FAs were completed using the relative response factor (RRF) method (Sparkman et al., 2011; L. 


308

309

Dean, USDA, Raleigh, North Carolina, U.S.A., personal communication), and area ratios were compared to the internal standard (KEL-FIM-FAME-5 Mixture, Matreya, LLC, State College, Pennsylvania, U.S.A.).

2.8 $\underline{\text { Statistics }}$ - Data were analyzed by either a one-way or two-way ANOVA with repeated measures (SAS v.9.2 - SAS Institute, Inc., 2009). Treatment effects were considered significant at $\mathrm{p} \leq 0.05$ (one-sided). Type 3 Tests of Fixed Effects were completed to ensure that controls were not significantly different, and indicated that replicates were similar.

\section{Results}

3.1 Low $\mathrm{N}$ and/or $\mathrm{P}$ - Cell production by D. viridis UTEX ZZ1150 under $\mathrm{N}$ or $\mathrm{P}$ deprivation or $10 \%$ limitation (i.e., $10 \%$ of nutrient-replete conditions) was so low that there was not enough material for FA analysis at the end of the 14-day duration. The cells were yellowish-whitish in color in comparison to the bright kelly-green controls.

Maximum cell production for the nutrient-replete cultures was $2.8 \times 10^{6}$ cells $/ \mathrm{mL}$ under 12:12 L:D and $2.3 \times 10^{6}$ cells/mL under CL (Fig. 1). Replicates grown in the lower nutrient regime (20\% of nutrient-replete conditions) attained maximal cell production of $1.8 \times 10^{6}$ cells $/ \mathrm{mL}$ in both light regimes. Cultures in the lower nutrient regime $(20 \% \mathrm{~N}, 20 \% \mathrm{P}$, or $20 \%$ $\mathrm{N}+\mathrm{P}$ relative to nutrient-replete conditions) under 12:12 L:D consistently had a lower $\mathrm{pH}$ than cultures grown under CL (Table 2). Whether in 12:12 L:D or CL, nutrient-replete controls were similar in $\mathrm{pH}$ throughout the growth phase (Table 2). Overall, low nutrient stress as $\mathrm{N}$ and/or $\mathrm{P}$ (20\% of replete conditions) did not promote an increase in total FAs under the 12:12 L:D regime or CL; thus, total FA content in D. viridis UTEX ZZ1150 was comparable in both light treatments under the low nutrient regimes (Fig. 2). 
3.2 Long-Term $\mathrm{pH}$ Stress - Adjusting the $\mathrm{pH}$ in exponentially growing culture revealed a potentially useful harvesting mechanism (also see Mixson et al. 2014). Addition of $2 \mathrm{~N}$ or $6 \mathrm{~N}$ sodium hydroxide $(\mathrm{NaOH})$ to the culture medium resulted in flocculation of Dunaliella cells to the bottom of the flasks or mass culture tubes (Fig. 3). At salinity 30, mass cultures that had been adjusted to $\mathrm{pH} 10$ recovered and the suspended algal populations began to increase cell production at 9 days post-inoculation (Fig. 4). In contrast, mass cultures at salinity 60 that had been adjusted to $\mathrm{pH} 10$ did not recover from the apparent adverse effect of high $\mathrm{pH}$. These high $\mathrm{pH}$-treated cultures attained maximum mean cell production $\left(\sim 1.25 \times 10^{6}\right.$ cells $\left./ \mathrm{mL}\right)$ by $\sim$ day 18 , whereas control mass cultures peaked in mean cell production $\left(\sim 2 \times 10^{6}\right.$ cells $\left./ \mathrm{mL}\right)$ by $\sim$ day 12 . Comparison of total FAs for the control mass cultures grown in salinity 30 and an initial pH of 8.3-8.4, versus mass cultures grown at salinity 30 and adjusted to $\mathrm{pH} 10$, showed that the highpH mass cultures recovered within 9 days (Fig. 4).

In the control mass cultures (salinity taken from 60 to 30; no $\mathrm{pH}$ adjustment), total FAs were highest on day $12(41.7 \pm 6.6 \%$; $\%$ total FAs \pm 1 standard error $[\mathrm{SE}])$ in comparison to day $3(9.6 \pm 1.7 \%)(\mathrm{p}<0.001)($ Table 3$)$. The treatment mass cultures (salinity taken from 60 to 30 $\mathrm{pH}$ adjusted to 10) behaved similarly; total FA content increased significantly on day 9 in comparison to day $3(\mathrm{p}=0.014)$ (Table 3$)$. At day 9 , tubes at salinity 60 taken to salinity 30 and adjusted to $\mathrm{pH} 10$ yielded the maximum total FA content $(55.6 \pm 3.1 \%)$ when compared to FA content on other days in that treatment, or to the FA content of control mass cultures (Fig. 5A).

To ensure that osmotic stress did not affect total FA content, control mass cultures (salinity taken from 60 to 60, or from 60 to 30; no $\mathrm{pH}$ adjustment) were compared. A similar trend in total FA production was observed for control mass cultures transferred from salinity 60 to 60, wherein total FAs increased throughout the growth phase (Fig. 5B). For control mass 
cultures transferred from salinity 60 to 60 , total FAs increased significantly on days 9, 12, and 14 in comparison to their total FA content on day $3(\mathrm{p}=<0.001$ to 0.019$)$ (Table 3$)$. Within the mass cultures transferred from salinity 60 to 30, total FAs increased significantly on all days in comparison to FA content on day 3 ( $\mathrm{p}<0.001$ to 0.003 ) (Table 3 ). There was no significant difference in total FA content between control mass cultures transferred from salinity 60 to 60 versus from salinity 60 to salinity 30 on each sampling date (Fig 5B). Thus, hypo-osmotic stress did not affect total FA content.

3.3 Short-Term $\mathrm{pH}$ Stress - As expected, responses to short-term $\mathrm{pH}$ stress were strain-specific. Dunaliella tertiolecta CCAP 19/9 significantly increased in total FAs when exposed to $\mathrm{pH} 7$, but only after $24 \mathrm{hr}$ of exposure to pH 10 (Fig. 6, left panels). After resuspension in pH 7 medium, there was a significant increase in total FAs at all time periods from $30 \mathrm{sec}$ to $24 \mathrm{hr}(\mathrm{p}=0.001$ to 0.015 ) (Table 4). However, the maximum total FA content was only $19.9 \pm 0.8 \%$, similar to the control total FA content $(15.3 \pm 1.5 \%)$. After resuspension in $\mathrm{pH} 10$ medium, there was a significant increase in total FAs at $24 \mathrm{hr}(\mathrm{p}=0.046)($ Table 4). The second tested strain, $D$. tertiolecta CCAP 19/24, increased total FA content when exposed to $\mathrm{pH} 7$ or $\mathrm{pH} 10$ media (Fig. 6 , right panels). Maximum total FA content $(35.6 \pm 1.1 \%)$ was measured $30 \mathrm{sec}$ after exposure to $\mathrm{pH} 7$, and was higher than the total FA content of controls $(30.8 \pm 0.6 \%)$ (Fig. 6, upper right panel). After resuspension in pH 10 medium, D. tertiolecta CCAP 19/24 significantly decreased in total FA content at $30 \mathrm{sec}, 1 \mathrm{hr}$, and $24 \mathrm{hr}(\mathrm{p}=0.001$ to 0.049$)$ (Table 4). The third strain, $D$. tertiolecta UEX 999, did not significantly change in total FA content when it was exposed to $\mathrm{pH}$ 7 medium, but significantly increased total FA content at $30 \mathrm{sec}, 5 \mathrm{~min}$, and $24 \mathrm{hr}$ after exposure to $\mathrm{pH} 10$ medium ( $\mathrm{p}=0.006$ to 0.035$)$ (Table 4; Fig. 7, left panels). The maximum total FA 
content for this strain was $23.9 \pm 1.2 \%$ at $30 \mathrm{sec}$ when resuspended in $\mathrm{pH} 10$ medium, whereas control cultures had $18.6 \pm 1.5 \%$ total FA content

The D. viridis UTEX ZZ1150 strain significantly decreased in total FA content ( $\mathrm{p}=$

0.005 to 0.021 ), in comparison to its FA content on day 3 , when it was exposed to either $\mathrm{pH} 7$

(except at $5 \mathrm{~min}$ when there was a significant increase to $43.3 \pm 5.5 \% ; \mathrm{p}=0.004$ ) or $\mathrm{pH} 10$

medium (Table 4; Fig. 7, right panels). When resuspended in $\mathrm{pH} 10$ medium, this strain significantly decreased its total FA content at every time period tested from $30 \mathrm{sec}$ to $24 \mathrm{hr}$ (p < 0.001 to 0.003$)$ (Table 4).

3.4 $\underline{\mathrm{CO}}_{2}$ Pulses $\mathrm{x}$ Light Regime - The $\mathrm{pH}$ decreased from $\sim 9.3$ to $\sim 8.0$ (12:12 L:D) (Fig. 8A) or from $\sim 9.8$ to $\sim 8.4$ (CL) (Fig. $8 \mathrm{~B}$ ) when mass cultures received pulsed $\mathrm{CO}_{2}$ enrichment.

Maximum cell production of mass-cultured Dunaliella viridis UTEX ZZ1150 under 12:12 L:D or continuous light (CL) occurred on day 11 (Fig. 8). Tubes under 12:12 L:D $\pm \mathrm{CO}_{2}$, or under CL without pulsed $\mathrm{CO}_{2}$, attained maximal cell production of $1.4 \times 10^{6}$ cells/mL, and maximal cell production was comparable in mass cultures under $\mathrm{CL}+$ pulsed $\mathrm{CO}_{2}\left(1.9 \times 10^{6}\right.$ cells $\left./ \mathrm{mL}\right)$ by day 11 (Fig. 8). Mass cultures under $\mathrm{CL}+$ pulsed $\mathrm{CO}_{2}$ were much darker green in color than cultures under 12:12 L:D \pm pulsed $\mathrm{CO}_{2}$, or under $\mathrm{CL}$ without pulsed $\mathrm{CO}_{2}$ (Fig. 9).

Total FAs increased throughout growth to senescence of mass-cultured $D$. viridis UTEX ZZ1150 (Fig. 10). The total FA content significantly increased at days 9 and 12, in comparison to day 6, in mass cultures grown under 12:12 L:D \pm pulsed $\mathrm{CO}_{2}(\mathrm{p}<0.001$ to 0.003$)$, and in cultures grown under $\mathrm{CL} \pm$ pulsed $\mathrm{CO}_{2}$ ( $\mathrm{p}<0.001$ to 0.002) (Table 5). By day 12, mass cultures in $\mathrm{CL}+$ pulsed $\mathrm{CO}_{2}$ had a maximal total FA content of $42.8 \pm 8.2 \%$, significantly higher than that of cultures in $\mathrm{CL}$ without pulsed $\mathrm{CO}_{2}(22.6 \pm 0.1 \%)(\mathrm{p}=0.026)($ Table 6, Fig. 10B). Overall, cultures with pulsed $\mathrm{CO}_{2}$ enrichment had significantly higher total FAs than cultures without 
400 pulsed $\mathrm{CO}_{2}$, whether in a 12:12 L:D or CL regime $(\mathrm{p}=0.009)$ (Table 6). By day 12, comparison of cultures with pulsed $\mathrm{CO}_{2}$ revealed that this $D$. viridis strain had significantly higher maximal total FA content in CL $(42.8 \pm 8.2 \%)$ than in 12:12 L:D $(31.5 \pm 1.8 \%)(\mathrm{p}=0.049)$ (Table 6, Fig. $10)$.

\section{Discussion}

4.1 Low Nitrogen and/or Phosphorus - N accounts for up to $10 \%$ of the total dry weight in exponentially growing, non-siliceous algae (Kaplan et al., 1986; Wetzel, 2001). Some algae have been shown to prefer $\mathrm{NH}_{4}{ }^{+}$over other $\mathrm{N}$ forms, with $\mathrm{NO}_{3}{ }^{-}$taken up only after $\mathrm{NH}_{4}{ }^{+}$is depleted (Kaplan et al., 1986; Glibert et al., 2015). Yet, $\mathrm{NH}_{4}{ }^{+}$can be inhibitory or toxic to cells when used as the sole source of N (Kaplan et al., 1986; Glibert et al., 2015) and, thus, has been referred to as a "paradoxical" nutrient (Britto and Kronzucker, 2002). The threshold of toxicity 412 responses to $\mathrm{NH}_{4}{ }^{+}$is species-specific, and also can be strain-specific (Glibert et al., 2015). In 413 this study, $\mathrm{NH}_{4}{ }^{+}$appeared to inhibit both of the tested Dunaliella strains even at the lowest 414 concentrations used, and resulted in poor growth.

$415 \quad \mathrm{~N}$ deficiency might have been expected to increase lipid accumulation, partly because 416 storage and membrane lipids do not contain N (Roessler, 1990). These lipids can continue to be 417 synthesized while synthesis of $\mathrm{N}$-containing compounds such as proteins and nucleic acids is 418 slowed or stopped as $\mathrm{N}$ becomes limiting (Roessler 1990). Inorganic N limitation can promote 419 an increase in neutral lipids in various chlorophytes, such as Chlorella spp. (Ben-Amotz et al., 420 1985; Roessler, 1990), Nannochloropsis spp. (Suen et al., 1987; Rodolfi et al., 2009), and 421 Chlamydomonas reinhardtii (Wang et al., 2009; Moellering and Benning, 2010). Studies with 422 Dunaliella strains have yielded varying results, as shown for various other microalgae (e.g., 423 Shifrin and Chisholm, 1981; Lombardi and Wangersky, 1995, and references therein). Some 
strains within $D$. bardawil, D. primolecta, D. tertiolecta, and D. viridis have not increased total lipid content in response to $\mathrm{N}$ deficiency (Shifrin and Chisholm, 1981; Ben-Amotz et al., 1985; Uriarte et al., 1993; Adam, 1997; Gordillo et al., 1998, present study), while strains within $D$. salina and D. tertiolecta have produced more lipids (Weldy and Huesemann, 2007; Chen et al., 2011; Davidi et al., 2012; Arias-Forero et al., 2013). Here, several strains of D. tertiolecta and the unique strain D. viridis UTEX ZZ1150 did not increase neutral lipids in response to low N stress.

Luxury consumption of P by microalgae is a well-known phenomenon (Beardall et al., 2001; Wetzel 2001, and references therein). Under P-limited conditions, algae exhibit reduced 433 photosynthetic capacity, increased $\mathrm{P}$ uptake, and P-dependent transients in oxygen evolution 434 (Beardall et al., 2001). Few studies have examined the potential role of P limitation or 435 deprivation in enhancing lipid production in microalgae. The diatom Phaeodactylum tricornutum 436 significantly increased its total FA content in medium without $\mathrm{P}$ in comparison to its total FA 437 content in P-replete medium, but this response has not been found in D. tertiolecta (Siron et al., 438 1989; present study) or D. viridis UTEX ZZ1150 (present study).

441 cultures were adjusted from $\mathrm{pH}$ 8.3-8.4 to $\mathrm{pH}$ 10. Spontaneous flocculation or auto-flocculation 442 occurred due to the sharp increase in $\mathrm{pH}$ (see Richmond and Becker, 1986). The Dunaliella cells 443 excreted sufficient glycerol to enhance their flocculation and removal from the water column 444 (Mixson et al., 2014). The combination of high salinity (60) and $\mathrm{pH}$ adjustment to 10 led to no 445 recovery of the culture from flocculation/settlement. By contrast, in media with salinity 30 and $446 \mathrm{pH} \mathrm{10,} \mathrm{the} \mathrm{Dunaliella} \mathrm{cultures} \mathrm{were} \mathrm{able} \mathrm{to} \mathrm{recover} \mathrm{from} \mathrm{flocculation/settlement.} \mathrm{Although} \mathrm{the}$ 447 treated cultures maintained lower maximal cell densities than the controls, total FAs increased by 
the end of the experiment. The only significant difference between the control and high $\mathrm{pH}-$ treated cultures occurred on day 9 , when cultures in the high $\mathrm{pH}$ treatment increased total FA content to $\sim 56 \%$, whereas the total FA content of controls was only 29\%. Gardner et al. (2011) reported that the chlorophycean, Scenedesmus sp. produced appreciable lipids in alkaline medium ( $\mathrm{pH}>9$ ); however, this observation was also correlated with $\mathrm{N}$ depletion. In this study, D. viridis UTEX ZZ1150 did not increase total FA content in response to $\mathrm{N}$ limitation, suggesting that high $\mathrm{pH}$ alone increased total FA content in this mass-cultured $D$. viridis strain.

4.4 Short-term $\mathrm{pH}$ Stress - Responses to short-term $\mathrm{pH}$ stress were strain-specific but, in general, increases in total FA content were not observed. After exposure to $\mathrm{pH} 7$, only Dunaliella tertiolecta CCAP 19/9 significantly increased in total FA content at every time point (30 sec to $24 \mathrm{hr}$ ) (note that $D$. viridis also increased total FA production, but only 5 min after exposure; at every other time point, this strain significantly decreased total FA content in response to $\mathrm{pH} 7$ ). Exposure of cultures to low or high $\mathrm{pH}$ led to variation among strains in total FA content as a short-term response. Except for D. tertiolecta CCAP 19/9 (at pH 10) and D. tertiolecta UTEX 999 (at $\mathrm{pH} 7$ ), the imposed short-term $\mathrm{pH}$ stress led to a decrease in total FA content in comparison to the total FA content of controls. It was expected that $\mathrm{pH} 10$ stress would stimulate FA production, as reported for other chlorophycean microalgae (e.g. Scenedesmus spp.; Gardner et al., 2012). As explained above, however, Dunaliella spp. have differed in responses to environmental stressors relative to other chlorophyceans. It should also be noted that Gardner et al. (2012) did not quantify lipid production but, rather, observed an increase in Nile Red fluorescence that was calibrated to TAG concentrations. 
4.5 $\underline{\mathrm{CO}}_{2} \underline{\mathrm{x} \text { Light }}$ - In this experiment, total FAs accumulated throughout the growth cycle for mass-cultured Dunaliella viridis UTEX ZZ1150, with highest production by early senescence. Most microalgae have been found to accumulate most lipids during stationary phase or senescence rather than during active growth (Henderson and Sargent, 1989; Hodgson et al., 1991; Brown et al., 1996; Pond and Harris, 1996; Hu et al., 2008 and references therein; Yoo et al., 2010). Aging or senescence of algal cultures is accompanied by a change in lipid biosynthesis pathways from the chloroplast or other cellular membranes to neutral storage lipids (Qunju et al., 2015). Additionally, most algae that have been tested do not grow well in continuous light (e.g., Carvalho and Malcata, 2004; Lorenz et al., 2005; Sforza et al., 2012). Typically during the dark cycle, plant cells use FAs that accumulated in the light period for energy (Guckert and Cooksey, 1990; Gardner et al., 2012).

Mass-cultured D. viridis UTEX ZZ1150 grown under CL+ pulsed $\mathrm{CO}_{2}$ had maximal total FA content by day 12 (42.8\%) (Fig. 10). In marked contrast to what is known for most microalgae that have been examined, in CL these cultures continually maintained photosynthesis (Mixson, 2013). Without a dark cycle to break down carbon products, the excess carbon as $\mathrm{CO}_{2}$ apparently was converted by D. salina cells into FAs. Gardner et al. (2012) investigated adding sodium bicarbonate $\left(\mathrm{NaHCO}_{3}\right)$ to $\mathrm{N}$-depleted cultures. Adding bicarbonate triggered FA production in N-deprived Scenedesmus spp. under 14:10 L:D. Here, D. viridis UTEX ZZ1150 did not respond to stress imposed by low $\mathrm{N}$ and/or P. The combination of CL (continuous light) and pulsed $\mathrm{CO}_{2}$ enrichment significantly increased total FA production by $D$. viridis UTEX ZZ1150 when compared to cultures grown under CL alone, or in a 12:12 L:D period \pm enriched $\mathrm{CO}_{2}$. 
Mass cultures of $D$. viridis UTEX ZZ1150 that received both CL and pulsed $\mathrm{CO}_{2}$ had

much more green pigment than cultures under 12:12 L:D \pm pulsed $\mathrm{CO}_{2}$, or cultures under $\mathrm{CL}$ without pulsed $\mathrm{CO}_{2}$. It was hypothesized that the additional available $\mathrm{CO}_{2}$ resulted in enhanced chlorophyll $a$ production, as has been found in other work. For example, Tripathi et al. (2001) found that certain strains of Chlorella vulgaris (Chlorophyta, Trebouxiophyceae), Scenedesmus obliquus (Chlorophyta, Chlorophyceae), and the cyanobacteria Spirulina, Nostoc, and Stigonema exhibited a 2- to 3-fold increase in both chlorophyll and carotenoid content when cells were exposed to $2 \% \mathrm{CO}_{2}$ after 21 days and 10 days, respectively. Another experiment investigated the effects of $\mathrm{CO}_{2}$ deprivation on chlorophyll content in the cyanobacterium Synechococcus lividus (Miller and Hold 1977). Within $100 \mathrm{hr}$ of $\mathrm{CO}_{2}$ depletion, the chlorophyll $a$ content significantly declined below that of control $\left(\mathrm{CO}_{2}\right.$-replete $)$ cultures. When the $\mathrm{CO}_{2}$-depleted cultures were given $\mathrm{CO}_{2}$ for $48 \mathrm{hr}$, the chlorophyll $a$ content increased to comparable levels as in the control cultures.

As mentioned, this strain originated in the CAAE as a contaminant in a UTEX D. salina culture, and grew well in mass culture under continuous light with maintenance of high lipid production (Mixson, 2013). Under both low- and high-salinity stress in additional experiments with both bench-scale and mass cultures (Mixson, 2013; Mixson et al., submitted), D. viridis UTEX ZZ1150 also grew well under continuous light, unlike 13 other tested strains within five Dunaliella spp. In other work the same strain, provided by the CAAE, was tested in small batch cultures along with one strain each of three other Dunaliella species, for response to changes in light duration $\mathrm{x}$ growth temperature (Srirangan et al. 2015). Unlike the strains representing the other three Dunaliella species, the rate of cell division in D. viridis UTEX ZZ1150 increased under continuous light. A shift from $25^{\circ}$ to $35^{\circ} \mathrm{C}$ under continuous light did not significantly alter 
523

the rate of cell division, but increased triacylglycerol content per cell several-fold. Lauric acid was incorporated into triacylglycerol after $24 \mathrm{hr}$ in continuous light.

\section{Conclusion}

Environmental stressors of high $\mathrm{pH}+$ low salinity, low $\mathrm{pH}$ (short-term), and CL with pulsed $\mathrm{CO}_{2}$ significantly enhanced lipid production as total FAs, on average, by $56 \%$, 43\%, and $42 \%$, respectively, in comparison to the lipid content of controls (23\%). In contrast to reports for other chlorophytes, low or depleted $\mathrm{N}$ and/or $\mathrm{P}$, high $\mathrm{pH}$ alone, and 12:12 L:D with pulsed $\mathrm{CO}_{2}$ in these Dunaliella strains did not increase total FA content. The response of Dunaliella cells to $\mathrm{pH}$ stress resulted in an increase of total FAs as both a short-term (sec to hr) and a long-term ( $\geq$ $24 \mathrm{hr}$ ) response. Enriched $\mathrm{CO}_{2}$ under continuous light promoted higher total FA production by the unique strain $D$. viridis UTEX ZZ1150 during active growth, rather than only during senescence as for most microalgae. High intraspecific variation in both growth and neutral lipid production was observed for the Dunaliella tertiolecta strains under each environmental stressor. Future research can build upon this study to further elucidate the complex relationships among environmental stressors and total FA production, toward harnessing Dunaliella as a source of sustainable biofuel. Of the strains tested here, the unique strain D. viridis UTEX ZZ1150 was shown to sustain both high maximal cell production and high total FA content in mass culture under continuous light or L:D periods, both during active growth and senescence. Among many published experiments testing lipid production among multiple species and strains of Dunaliella, this aberrant $D$. viridis strain, found as a contaminant of a commercial culture, appears to hold exceptional promise for sustainable biofuel production. 
541 We thank E. Allen and E. Alexander for assistance in algal culturing and media preparation, and

542 L. Dean for total FA analysis. Funding support was provided from the Charles A. and Anne 543 Morrow Lindbergh Foundation, and the National Science Foundation Emerging Frontiers in 544 Research and Innovation (EFRI-HyBi grant \#0937721).

\section{References}

Adam, M.S., 1997. Metabolic response of the halotolerant green alga Dunaliella bardawil to nitrogen : phosphorus ratios in batch culture. Folia Microbiol. 42, 357-360.

Arias-Forero, D., Hayashida, G., Aranda, M., Araya, S., Portilla, T., Garcías, A., Díaz-Palma, P., 2013. Protocol for maximizing the triglycerides-enriched lipids production from Dunaliella salina SA32007 biomass, isolated from the Salar de Atacama (northern Chile). Adv. Biosci. Biotech. 4, 830-839.

Azachi, M., Sadka, A., Fisher, M., Goldshlag, P., Gokhman, I., Zamir, A., 2002. Salt induction of fatty acid elongase and membrane lipid modifications in the extreme halotolerant alga Dunaliella salina. Plant Physiol. 129, 1320-1329.

Azov, Y., 1982. Effect of pH on inorganic carbon uptake in algal cultures. Appl. Environ. Microbiol. 43, 1300-1306.

Beardall, J., Berman, T., Heraud, P., Kadiri, M.O., Light, B.R., Patterson, G., Roberts, S., Sulzberger, B., Sahan, E., Uehlinger, U., Wood, B., 2001. A comparison of methods for detection of phosphate limitation in microalgae. Aquat. Sci. 63, 107-121.

Becker, E.W., 1994. Microalgae: Biotechnology and Microbiology. Cambridge University Press, New York. 
Ben-Amotz, A., Avron, M., 1983. On the factors which determine massive $\beta$-carotene accumulation in the halotolerant alga Dunaliella bardawil. Plant Physiol. 72, 593-597.

Ben-Amotz, A., and Avron, M., 1989. The Biotechnology of Mass Culturing Dunaliella for Products of Commercial Interest. In Creeswell, R.C., Rees, T.A.V, and Shah, N. [Eds.]. Algal and Cyanobacterial Biotechnology, Longman Scientific and Technical Press, New York, pp. 90-114.

Ben-Amotz, A., Tornabene, T.G., Thomas, W.H., 1985. Chemical profile of selected species of microalgae with emphasis on lipids. J. Phycol. 21, 72-81.

Ben-Amotz, A., Polle, J.E.W., Rao, D.V.S. (Eds.), 2009. The Alga Dunaliella: Biodiversity, Physiology, Genomics and Biotechnology. Science Publishers, Enfield (New Hampshire).

Britto, D.T., Kronzucker, H.J., 2002. $\mathrm{NH}_{4}{ }^{+}$toxicity in higher plants: a critical review. J. Plant Physiol. 159, 567-584.

Brown, A.P., Slabas, A.R., Rafferty, J.B., 2009. Fatty acid biosynthesis in plants - metabolic pathways, structure and organization. In: Wada H, Murata N (eds.) Lipids in Photosynthesis: Essential and Regulatory Functions. Advances in Photosynthesis and Respiration, Volume 30. Springer, Dordrecht, The Netherlands, pp 11-34.

Brown, M.R., Dunstan, G.A., Norwood, S.J., Miller, K.A., 1996. Effects of harvest stage and light on the biochemical composition of the diatom Thalassiosira pseudonana. J. Phycol. 32, 64-73.

Carvalho, A., Malcata, F.X., 2004. Optimization of $\omega$-3 fatty acid production by microalgae: crossover effects of $\mathrm{CO}_{2}$ and light intensity under batch and continuous cultivation modes. Mar. Biotechnol. 7, 381-388.

Chen, M., Tang, H., Ma, H., Holland, T.C., Ng, K.Y.S., Salley, S.O., 2011. Effect of nutrients on 
growth and lipid accumulation in the green algae Dunaliella tertiolecta. Bioresour. Technol. $102,1649-1655$.

Davidi, L., Katz, A., Pick, U., 2012. Characterization of major lipid droplet proteins from Dunaliella. Planta 236, 19-33.

El-Sheek, M.M., Rady, A.A., 1995. Effect of phosphorus starvation on growth, photosynthesis and some metabolic processes in the unicellular green alga Chlorella kessleri. Phyton 35, $139-151$.

Fields, M.W., Hise, A., Lohman, E.J., Bell, T., Gardner, R.D., Corredor, L., Moll, K., Peyton, B.M., Characklis, G.W., Gerlach, R., 2014. Sources and resources: importance of nutrients, resource allocation, and ecology in microalgal cultivation for lipid accumulation. Appl. Microbiol. Biotechnol. 98, 4805-4816.

Føyn, B. 1934. Lebenszyklus, Cytologie und Sexualiät der Chlorophycee Cladophora suhriana Kützing. Arch. Protistenk. 83, 1-56.

García-González, M., Moreno, J., Cañavate, J.P., Anguis, V., Prieto, A., Manzano, C., Florencio, F.J., Guerrero, M.G., 2003. Conditions for open-air outdoor culture of Dunaliella salina in southern Spain. J. Appl. Phycol. 15, 177-184.

Gardner, R., Peters, P., Peyton, B., Cooksey, K.E., 2011. Medium pH and nitrate concentration effects on accumulation of triglycerol in two members of the chlorophytes. J. Appl. Phycol. 23, 1005-1016.

605 Gardner, R.D., Cooksey, K.E., Mus, F., Macur, R., Moll, K., Eustance, E., Carlson, R.P., 606 Gerlach, R., Fields, M.W., Peyton, B.M., 2012. Use of sodium bicarbonate to stimulate 607 triacylglycerol accumulation in the chlorophyte Scenedesmus sp. and the diatom 608 Phaeodactylum tricornutum. J. Appl. Phycol. 24, 1311-1320. 
Glibert, P.M., F.P. Wilkerson, F.P., Dugdale, R.C., Raven, J.A., Dupont, C.L., Leavitt, P.R., Parker, A.E., Burkholder, J.M., Kana, T.M. 2015. Pluses and minuses of ammonium and nitrate uptake and assimilation by phytoplankton and implications for productivity and community composition, with emphasis on nitrogen-enriched conditions. Limnol. Oceanogr. 61: 165-197.

Gordillo, F.J.L., Goutx, M., Figueroa, F.L., Niell, F.X., 1998. Effects of light intensity, $\mathrm{CO}_{2}$ and nitrogen supply on lipid class composition of Dunaliella viridis. J. Appl. Phycol. 10, 135144.

Griffiths, M.J., van Hille, R.P., Harrison, S.T.L., 2010. Selection of direct transesterification as the preferred method for assay of fatty acid content of microalgae. Lipids 45, 1053-1060.

Guckert, J.B., Cooksey, K.E., 1990. Triglyceride accumulation and fatty acid profile changes in Chlorella (Chlorophyta) during high pH-induced cell cycle inhibition. J. Phycol. 26, 72-79.

Guillard, R.R.L., 1975. Culture of phytoplankton for feeding marine invertebrates. In: Smith, W.L., Chanley, M.H. (Eds.), Culture of Marine Invertebrate Animals. Plenum Press, New York (New York). pp. 29-60.

Guillard, R.R.L., 2005. Purification methods for microalgae. In: Andersen, R.A. [Ed.] Algal Culturing Techniques. Elsevier Academic Press, Burlington, Massachusetts. pp. 117-132.

Guillard, R.R.L., Hargraves, P.E., 1993. Stichochrysis immobilis is a diatom, not a chrysophyte. Phycologia 32, 234-236.

Henderson, R.J., Sargent, J.R., 1989. Lipid composition and biosynthesis in ageing cultures of the marine cryptomonad, Chroomonas salina. Phytochemistry 28, 1355-1361.

Hodgson, P.A., Henderson, R.J., Sargent, J.R., Leftley, J.W., 1991. Patterns of variation in the lipid class and fatty acid composition of Nannochloropsis oculata (Eustigmatophyceae) during batch culture. I. The growth cycle. J. Appl. Phycol. 3, 169-181.

Kaplan, D., Richmond, A.E., Dubinsky, Z., Aaronson, S., 1986. Algal nutrition. In: Richmond, 
Kawachi, M., Noël, M.-H., 2005. Sterilization and sterile technique. In: Andersen, R.A. (Ed.) Algal Culturing Techniques. Elsevier Academic Press, Burlington (Massachusetts), pp. 6563681.

637 Lombardi, A.T., Wangersky, P.J., 1995. Particulate lipid class composition of three marine 638 phytoplankters Chaetoceros gracilis, Isochrysis galbana (Tahiti), and Dunaliella tertiolecta 639 grown in batch culture. Hydrobiologia 306, 1-6.

640 Lorenz, M., Friedl, T., Day, J.G., 2005. Perpetual Maintenance of Actively Metabolizing Microalgal

641 Cultures in Andersen, R.A. (Ed.), Algal Culturing Techniques. Elsevier Academic Press, 642 Massachusetts, pp. 145-156.

643 Lynch, D.V. Thompson, Jr., G.A., 1982. Low temperature-induced alterations in the chloroplast and 644 microsomal membranes of Dunaliella salina. Plant Physiol. 69, 1369-1375.

645 Miller, L.S., Holt, S.C. 1977. Effect of carbon dioxide on pigment and membrane content in 646 Synechococcus lividus. Arch. Microbiol. 115, 185-198.

647 Mixson, S.M., 2013. Dunaliella spp. under environmental stress: Enhancing Lipid Production 648 and Optimizing Harvest. Ph.D. thesis, Department of Plant Biology, North Carolina State 649 University, Raleigh.

650 Mixson, S.M., Burkholder, J.M., Zimba, P., submitted. Environmental stressors and lipid 651 production by Dunaliella spp. I. Salinity. J. Exp. Mar. Biol. Ecol.

652 Mixson, S.M., Stikeleather, L.F., Simmons, O.D. III, Wilson, C.W., Burkholder, J.M., 2014. pH653 induced flocculation, indirect electrocoagulation, and hollow fiber filtration techniques for 654 harvesting the saltwater microalga Dunaliella. J. Appl. Phycol., DOI 10.1007/s10811-013-0232-z. 655 Moellering, E.R., Benning, C., 2010. RNA interference silencing of a major lipid droplet protein 
affects lipid droplet size in Chlamydomonas reinhardtii. Eukaryot. Cell. 9, 97-106.

Msanne, J., Xu, D., Konda, A.R., Casas-Mollano, J.A., Awada, T., Cahoon, E.B., Cerutti, H., 2012. Metabolic and gene expression changes triggered by nitrogen deprivation in the photoautotrophically grown microalgae Chlamydomonas reinhardtii and Coccomyxa sp. C169. Phytochemistry $75,50-59$.

Oren A., 2005. A hundred years of Dunaliella research: 1905-2005. Saline systems 1, 1-14.

Peeler, T.C., Thompson, Jr., G.A., 1990. Effects of light on phospholipid metabolism in Dunaliella salina. Physiol. Plant. 78, 324-330.

Pinkart, H.C., Devereux, R., Chapman, P.J., 1998. Rapid separation of microbial lipids using solid phase extraction columns. J. Microb. Meth. 34, 9-15.

Pond, D.W., Harris, R.P., 1996. The lipid composition of the coccolithophore Emiliania huxleyi and its possible ecophysiological significance. J. Mar. Biol. Assoc. UK 76, 579-594.

Qunju, H., Wenzhou, X., Shikun, D., Tao, L., Fangfang, Y., Qikun, J., Guanghua, W., Hualian, W., 2015. The influence of cultivation period on growth and biodiesel properties of microalga Nannochloropsis gaditana 1049. Bioresour. Technol. 192, 157-164.

671 Richmond, A., E.W. Becker., 1986. Technological aspects of mass cultivation - a general 672 outline. In: Richmond, A. (Ed.), Handbook of Microalgal Mass Culture. CRC Press, 673 Boca Raton (Florida), pp. 245-263.

674 Rodolfi, L., Zittelli, G.C., Bassi, N., Padovani, G., Biondi, N., Gonini, G., Tredici, M.R., 2009. 675 Microalgae for oil: strain selection, induction of lipid synthesis and outdoor mass cultivation 676 in a low-cost photobioreactor. Biotechnol. Bioeng. 102, 100-112.

677 Roessler, P.G., 1990. Environmental control of glycolipid metabolism in microalgae: commercial 678 implications and future research directions. J. Phycol. 26, 393-399. 
Sager, R., Granick, S., 1953. Nutritional studies with Chlamydomonas reinhardtii. Ann. New York Acad. Sci. 56, 831-838.

681 Santos, A.M., Janssen, M., Lamers, P.P., Evers, W.A.C., Wijffels, R.H., 2012. Growth of oil accumulating microalga Neochloris oleoabundans under alkaline-saline conditions. Bioresour. Technol. 104, 593-599.

SAS Institute, Inc., 2009. SAS/STAT Guide for Personal Computers, version 9.3. SAS Institute, Inc., Cary (NC).

Sforza, E., Simionato, D., Giacometti, G.M., Bertucco, A., Morosinotto, T., 2012. Adjusted light and dark cycles can optimize photosynthetic efficiency in algae growing in photobioreactors. PLoS ONE 7:e38975.

Sharma, K.K., Schuhmann, H., Schenk, P.M., 2012. High lipid induction in microalgae for biodiesel production. Energies 5, 1532-1553.

Shifrin, N.S., Chisholm, S.W., 1981. Phytoplankton lipids: interspecific differences and effects of nitrate, silicate and light-dark cycles. J. Phycol. 17, 374-384.

Siron, R., Giusti, G., Berland, B., 1989. Changes in the fatty acid composition of Phaeodactylum tricornutum and Dunaliella tertiolecta during growth and under phosphorus deficiency. Mar. Ecol. Prog. Ser. 55, 95-100.

Song, D., Xi, B., Sun, J., 2016. Characterization of the growth, chlorophyll content and lipid accumulation in a marine microalgae [microalga] Dunaliella tertiolecta under different nitrogen to phosphorus ratios. J. Ocean. Univ. China (Oceanic and Coastal Sea Research) 15, 124-130.

Sparkman, O.D., Penton, Z.E., Kitson, F.G., 2011. Gas Chromatography and Mass Spectrometry: A Practical Guide, $2^{\text {nd }}$ Edition. Elsevier Inc., Burlington (Massachusetts). 611 pp.

Srirangan, S., Sauer, M.-L., Howard, B., Dvora, M., Dums, J., Backman, P., Sederoff, H., 2015. 
Suen, Y., Hubbard, J.S., Holzer, G., Tornabene, T.G., 1987. Total lipid production of the green alga Nannochloropsis sp. QII under different nitrogen regimes. J. Phycol. 23, 289-296.

Interaction of temperature and photoperiod increases growth and oil content in the marine microalgae Dunaliella viridis. PLoS One 10(5): e0127562. doi: 10.1371/journal.pone.0127562.

Taiz, L., Zeiger, E., 2006. Plant Physiology. $4^{\text {th }}$ Edition. Sinauer Associates, Inc., Massachusetts.

Takagi, M., Karseno, Yoshida, T., 2006. Effect of salt concentration on intracellular accumulation of lipids and triacylglyceride in marine microalgae Dunaliella cells. J. Biosci. Eng. 101, 223-226.

Thompson, P.A., Guo, M.-X., Harrison, P.J., Whyte, J.N.C., 1992. Effects of variation in temperature. II. On the fatty acid composition of eight species of marine phytoplankton. J. Phycol. 28, 488-497.

Tompkins, J., DeVille, M.M., Day, J.G., Turner, M.F., 1995. Culture Collection of Algae and Protozoa. Catalog of Strains. Ambleside (United Kingdom). 204 pp.

Tripathi, U., Sarada, R., Ravishankar, G.A. 2001. A culture method for microalgal forms using two-tier vessel providing carbon-dioxide environment: studies on growth and carotenoid production. World J. Microbiol. Biotechnol. 17, 325-329.

Uriarte, I., Farías, A., Hawkins, A.J.S., Bayne, B.L., 1993. Cell characteristics and biochemical composition of Dunaliella primolecta Butcher conditioned at different concentrations of dissolved nitrogen. J. Appl. Phycol. 5, 447-453.

Vollenweider, R.A. (Ed.), 1974. A Manual on Methods for Measuring Primary Production in Aquatic Environments, $2^{\text {nd }}$ Edition. Blackwell Scientific, Oxford.

Wang, Z.T., Ullrich, N., Joo, S., Waffenschmidt, S., Goodenough, U., 2009. Algal lipid bodies: stress induction, purification, and biochemical characterization in wild-type and starchless Chlamydomonas reinhardtii. Eukaryot. Cell. 8, 1856-1868. 
Weldy, C.S., Huesemann, M., 2007. Lipid production by Dunaliella salina in batch culture: effects of nitrogen limitation and light intensity. DOE J. Undergrad. Research V, 115-122.

Wetzel, R.G., 2001. Limnology: Lake and River Ecosystems, $3^{\text {rd }}$ Edition. Academic Press, California.

Wetzel, R.G., Likens, G.E., 2010. Limnological Analyses, $3^{\text {rd }}$ edition. WB Saunders, $731 \quad$ Pennsylvania.

732 Widjaja, A., Chien, C.-C., Ju, Y.-H, 2009. Study of increasing lipid production from fresh water 733 microalgae Chlorella vulgaris. J. Taiwan Inst. Chem. Eng. 40, 13-20.

734 Xu, X.-Q., Beardall, J., 1997. Effect of salinity on fatty acid composition of a green microalga 735 from an Antarctic hypersaline lake. Phytochemistry 45, 655-658.

736 Yilancioglu, K., Cokol, M., Pastirmaci, I., Erman, B., Cetiner, S., 2014. Oxidative stress is a 737 mediator for increased lipid accumulation in a newly isolated Dunaliella salina strain. PLoS $738 \quad$ ONE 9(3): e91957. doi:10.1371/journal.pone.0091957

739 Yongmanitchai, W., Ward, O.P., 1992. Growth and eicosapentaenoic acid production by $740 \quad$ Phaeodactylum tricornutum in batch and continuous culture systems. J. Am. Oil Chem. Soc. $741 \quad 69,584-590$.

742 Yoo, C., Jun, S.-Y., Lee, J.-Y., Ahn, C.-Y., Oh, H.-M., 2010. Selection of microalgae for lipid 743 production under high levels carbon dioxide. Bioresour. Technol. 101: S/71-S/74. 


\section{Figure Legends}

Fig. 1. Cell production of Dunaliella viridis UTEX ZZ1150 comparing low N and/or P (20\% of control, replete media concentration(s)): cell production under replete nutrient concentrations $(\boldsymbol{\square})$, low $\mathrm{N}(\boldsymbol{\Delta})$, low $\mathrm{P}(\diamond)$, and low $\mathrm{N}+\mathrm{P}(\bullet)$ with A) 12:12 L:D photoperiod and B) continuous light (CL). Data are given as means $\pm 1 \mathrm{SE}(\mathrm{n}=2)$.

Fig. 2. Total FAs (as percent dry weight, \%) in Dunaliella viridis UTEX ZZ1150 under N-replete and/or P-replete conditions (control) versus under low $\mathrm{N}$ and/or low $\mathrm{P}$ conditions. Each grouping includes 12:12 L:D and continuous light (CL) for control (nutrient-replete) versus low $\mathrm{N}$ and/or low P conditions. Data are given as means $\pm 1 \mathrm{SE}(\mathrm{n}=2)$.

Fig. 3. Photographs showing cell flocculation at either A) mass culture or B) bench scale in response to high pH. Arrows indicate the layer of Dunaliella cells at the bottom of each container.

Fig. 4. Photograph of mass culture tubes in the long-term $\mathrm{pH}$ stress experiment after 9 days: A) and B) control cultures, both grown in salinity 60; C) culture at salinity 60 and high $\mathrm{pH}-$ Dunaliella cells flocculated to the bottom of the containers after high $\mathrm{pH}$ adjustment and did not recover; D) culture at salinity 30 and high pH - Dunaliella cells flocculated after high pH adjustment, but recovered and cell production increased by day 9 .

Fig. 5. (A) Long-term pH stress: Total FAs (as percent by dry weight, \%) in Dunaliella viridis UTEX ZZ1150, with controls (no $\mathrm{pH}$ adjustment) compared to the treatment (pH 10 adjustment). In response to the high-pH adjustment, the algal populations flocculated and settled out to the bottom of culture vessels, then recovered after 9 days. Thus, samples were taken 3, 6, 9, and 12 days post-recovery. Controls were subsampled at 3-day intervals and at the end of the experiment on day 14 . The data were compared every 3 days, using a "baseline" reading at day 3 for controls or day 3 post-recovery for the treatment. Note that because mass cultures adjusted to $\mathrm{pH} 10$ at salinity 60 did not grow, data could not be collected from 
those cultures for total FAs. Data were collected at early senescence (day 14) for the control cultures, but not for treatments due to incomplete FA analysis. Significant differences from day 3 are indicated by an asterisk $(\mathrm{p} \leq 0.05)$ Data are given as means $\pm 1 \mathrm{SE}(\mathrm{n}=3)$. (B) Long-term $\mathrm{pH}$ stress and hypo-osmotic stress: Total FAs (as percent dry weight, \%) in Dunaliella viridis UTEX ZZ1150, comparing controls (no salinity adjustment) to the treatment (salinity adjusted from 60 to 30). Samples were taken in early exponential (day 6), mid-exponential (day 9), and late exponential (day 12) growth phases, and in early senescence (day 14). Significant differences from day 3 are indicated by an asterisk $(\mathrm{p} \leq 0.05)$. Data are given as means $\pm 1 \mathrm{SE}(\mathrm{n}=3)$.

Fig. 6. Short-term pH stress: Total FAs (as percent by dry weight, \%) in (left panels) Dunaliella tertiolecta CCAP 19/9 (left panels) and (right panels) D. tertiolecta CCAP 19/24 (right panels). Upper panels show response to low $\mathrm{pH}$ stress (initial $\mathrm{pH}$ adjusted from 9 to 7); lower panels show response to high $\mathrm{pH}$ stress (initial $\mathrm{pH}$ adjusted from 9 to 10). Significant differences from controls (= Before) are indicated by an asterisk $(\mathrm{p} \leq 0.05)$. Data are given as means \pm 1 SE $(\mathrm{n}=3)$.

Fig. 7. Short-term pH stress: Total FAs (as percent by dry weight, \%) in D. tertiolecta UTEX 999 (left panels) and D. viridis UTEX ZZ1150 (right panels). Upper panels show response to low $\mathrm{pH}$ stress (initial $\mathrm{pH}$ adjusted from 9 to 7); lower panels show response to high $\mathrm{pH}$ stress (initial $\mathrm{pH}$ adjusted from 9 to 10). Significant differences from controls (= Before) are indicated by an asterisk $(\mathrm{p} \leq 0.05)$. Data are given as means \pm 1 SE $(n=3)$.

Fig. 8. Mean cell production and $\mathrm{pH}$ values for mass culture of $D$. viridis UTEX ZZ1150 comparing responses in two light regimes, with vs. without pulsed $\mathrm{CO}_{2}$ enrichment: Cell production with (•) and without $(\checkmark)$ pulsed $\mathrm{CO}_{2}$, and pH values with $(\boldsymbol{\Delta})$ and without $(\boldsymbol{\square})$ pulsed $\mathrm{CO}_{2}$ with A) 12:12 L:D photoperiod or B) continuous light (CL). Arrows indicate where subsamples were taken for total FA analysis. The dashed vertical line indicates initiation of pulsed enrichment with $4 \mathrm{hr}$ of $\mathrm{CO}_{2}$ bubbling 
2

3

4790 daily for A) and B), and also the initiation of CL for all cultures in B). Data are given as means \pm 1 SE (n $791=4)$. . 10

795 Fig. 10. Total FAs (as percent by dry weight, \%) for mass-cultured D. viridis UTEX ZZ1150 \pm pulsed $796 \mathrm{CO}_{2}$ : A) Cultures grown under 12:12 L:D; and B) cultures grown under continuous light (CL) after 6 797 days. Samples were taken in mid-exponential (day 6), late-exponential (day 9) growth phases, and in 798 early senescence (day 12). Cultures were compared \pm pulsed $\mathrm{CO}_{2}$ enrichment. Significant differences 799 from day 6 are indicated by an asterisk $(p \leq 0.05)$. Data are given as means \pm 1 SE $(n=4)$. 

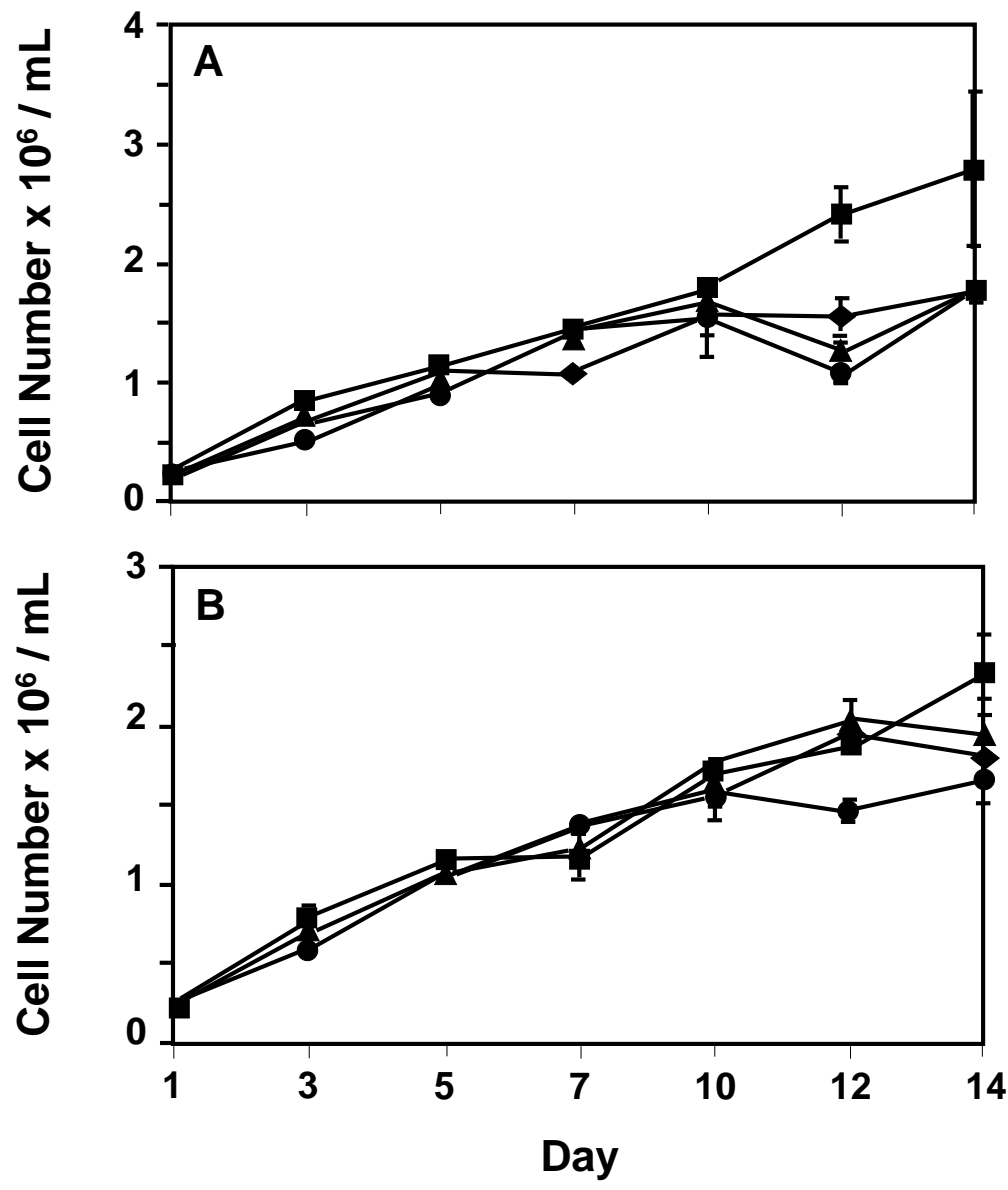


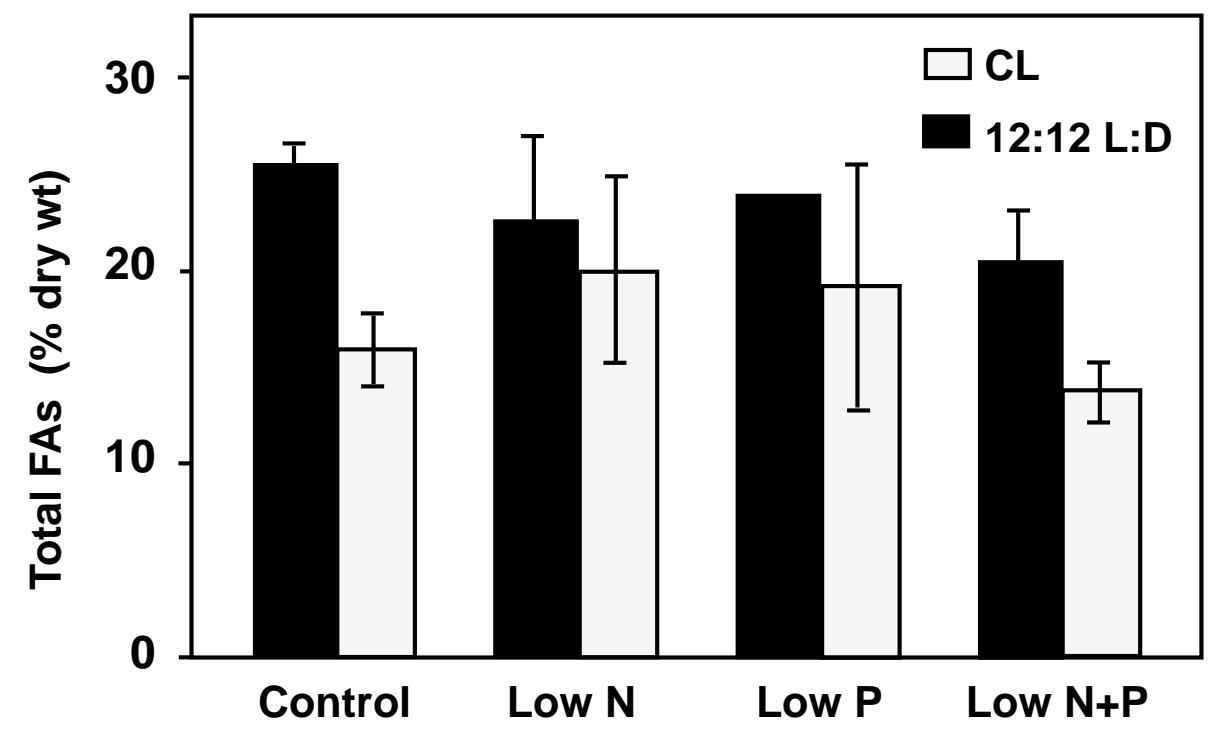


Figure 3

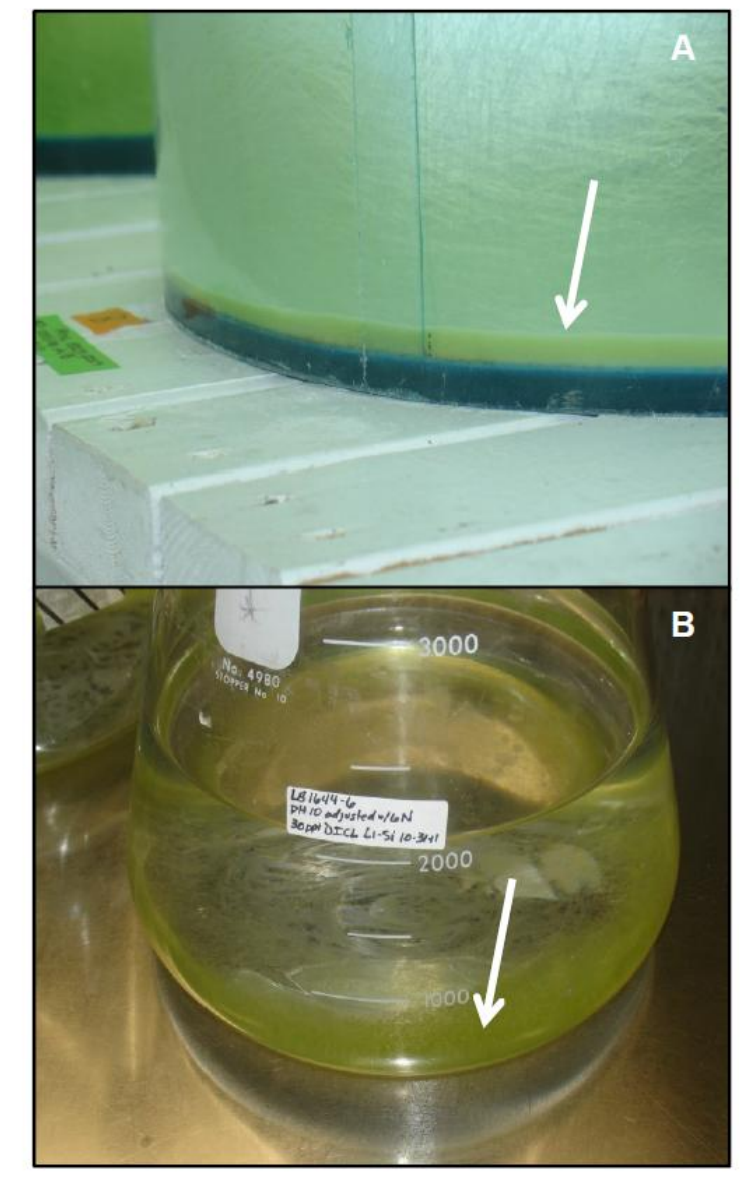


Figure 4

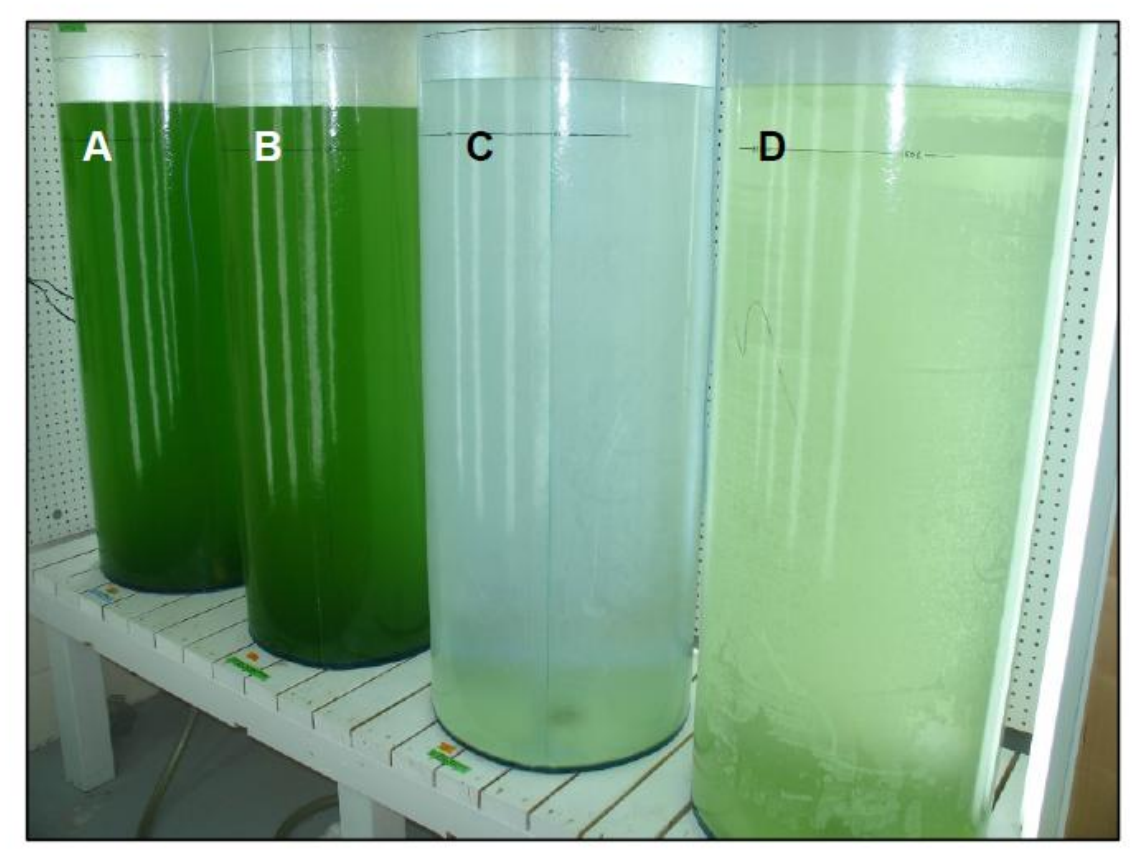



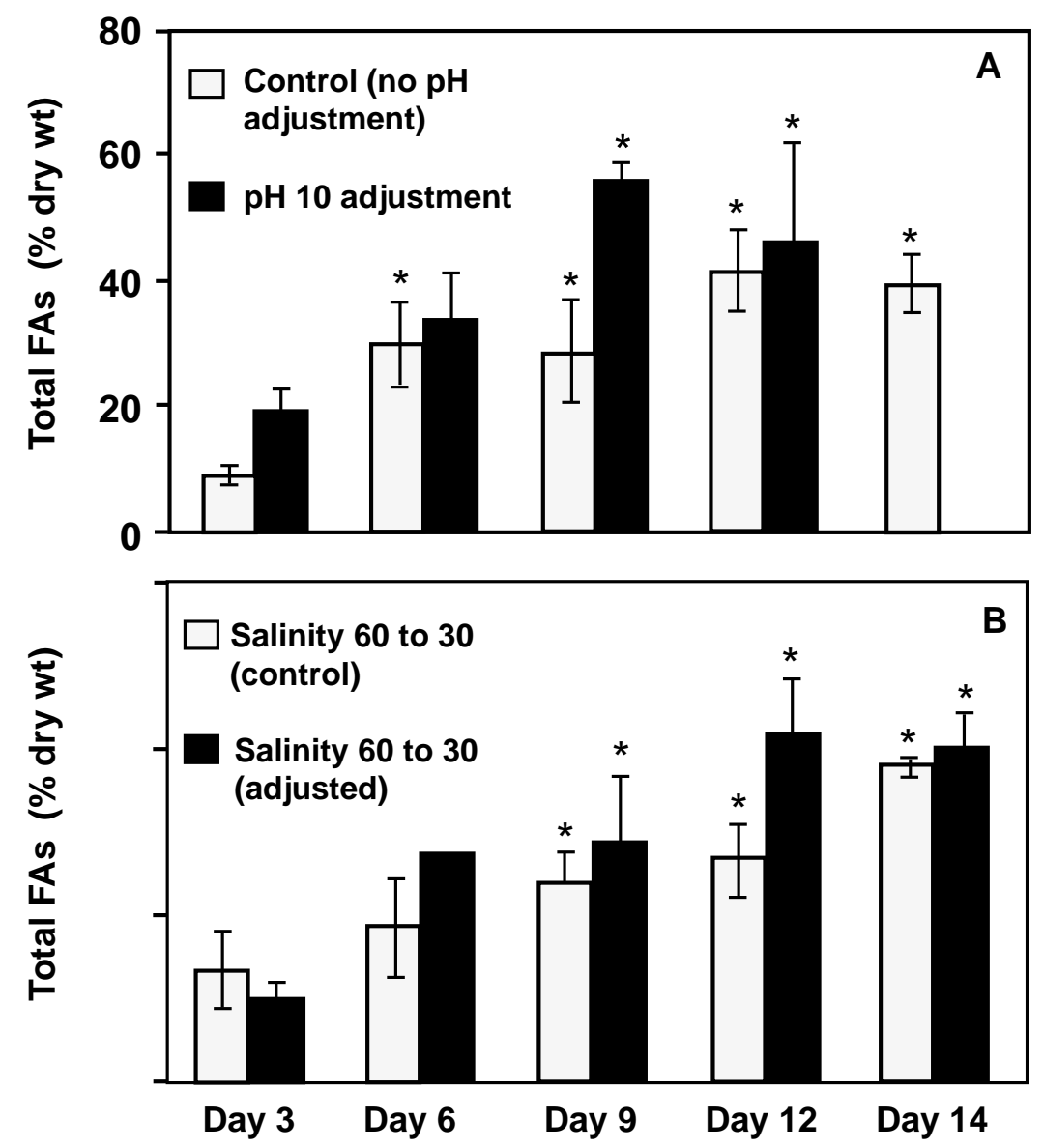

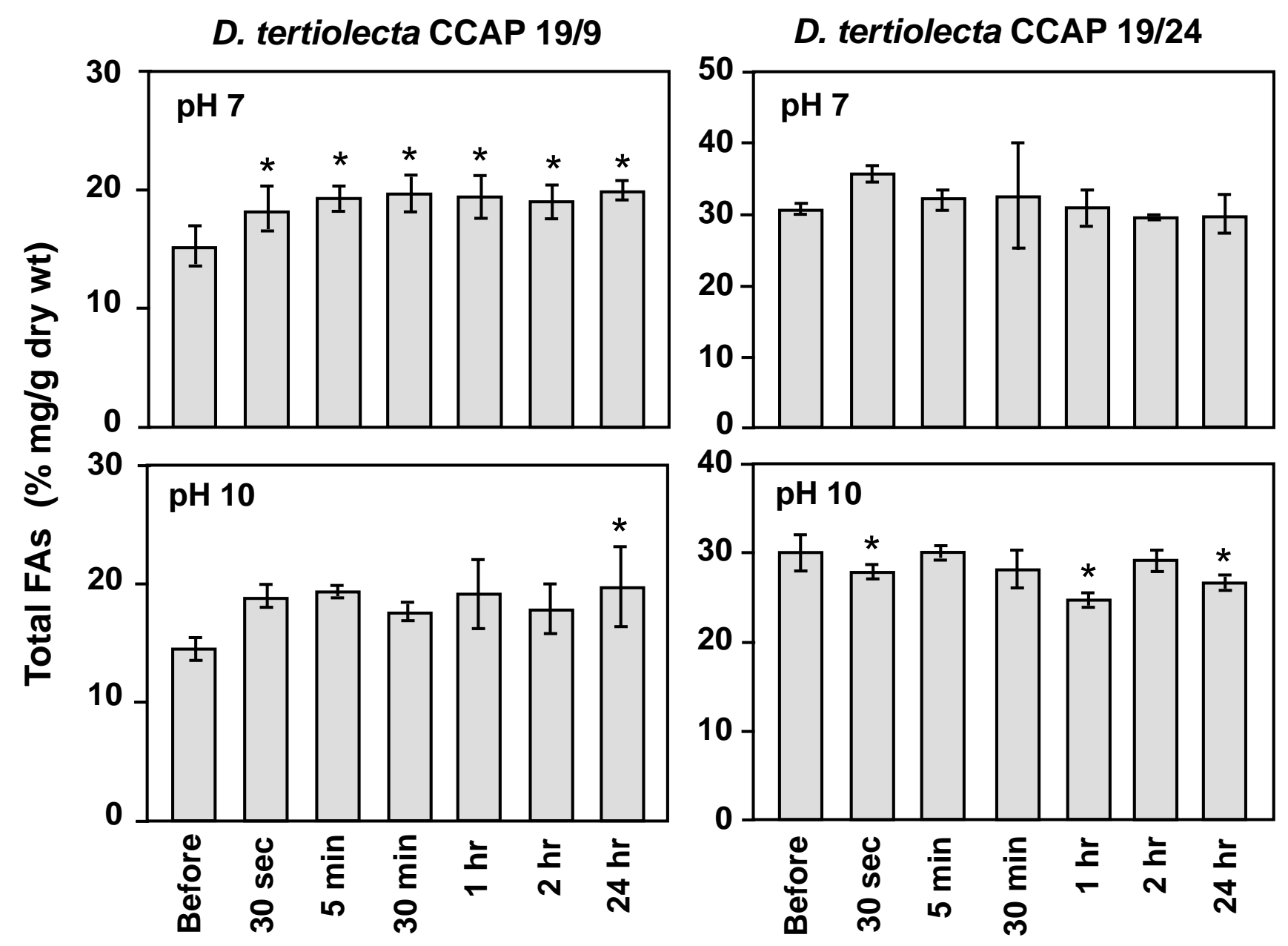


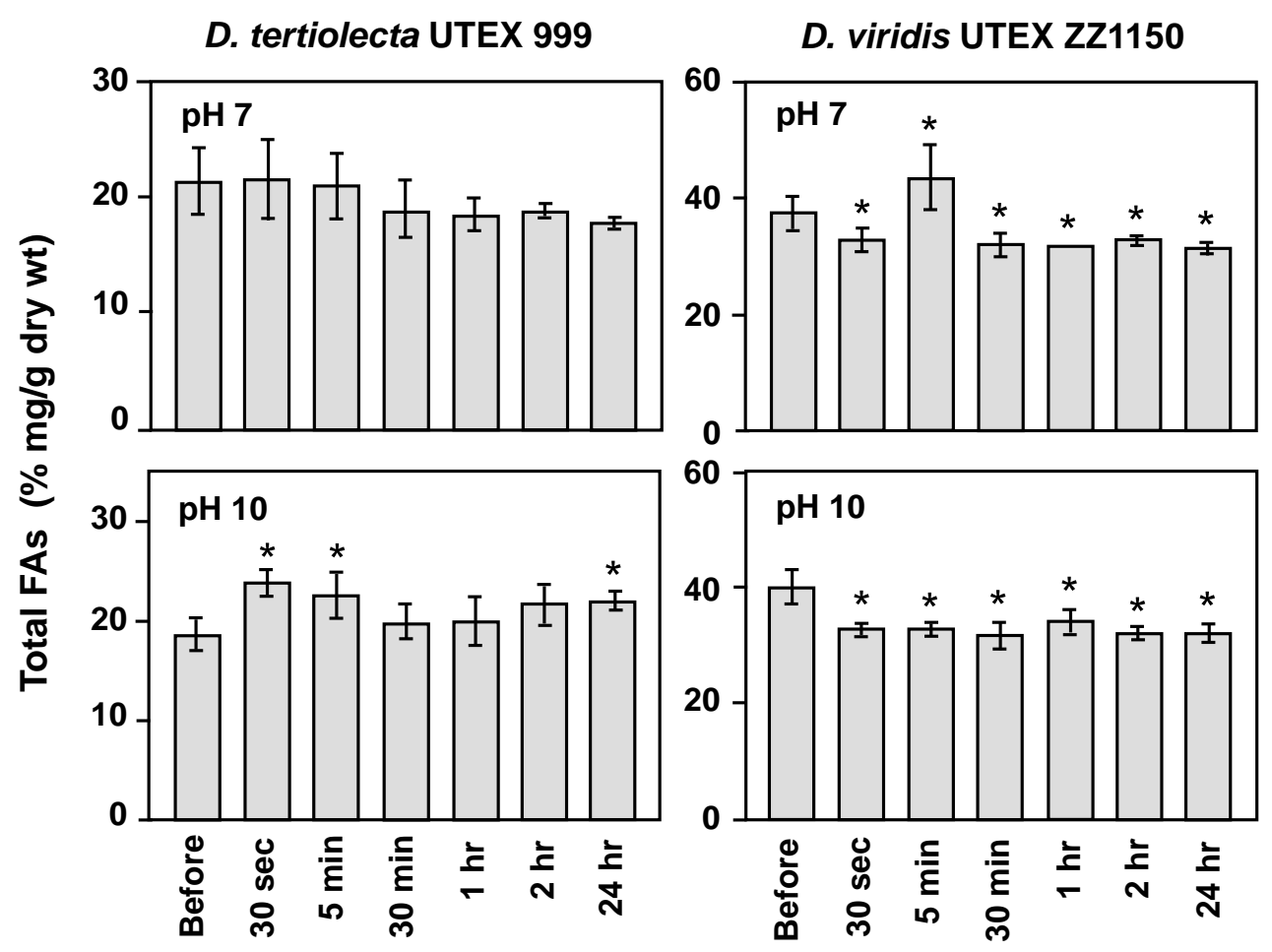



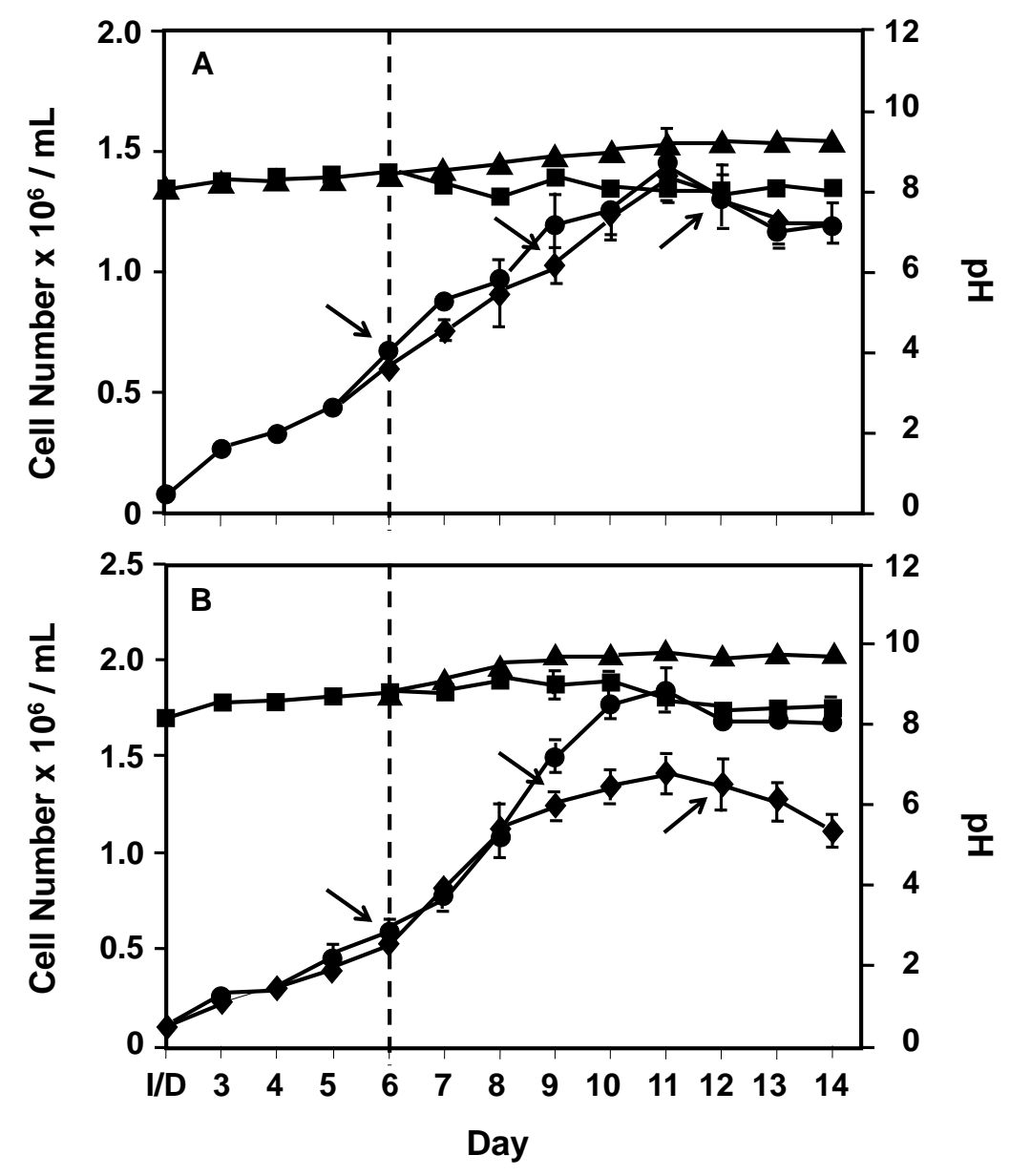
Figure 9
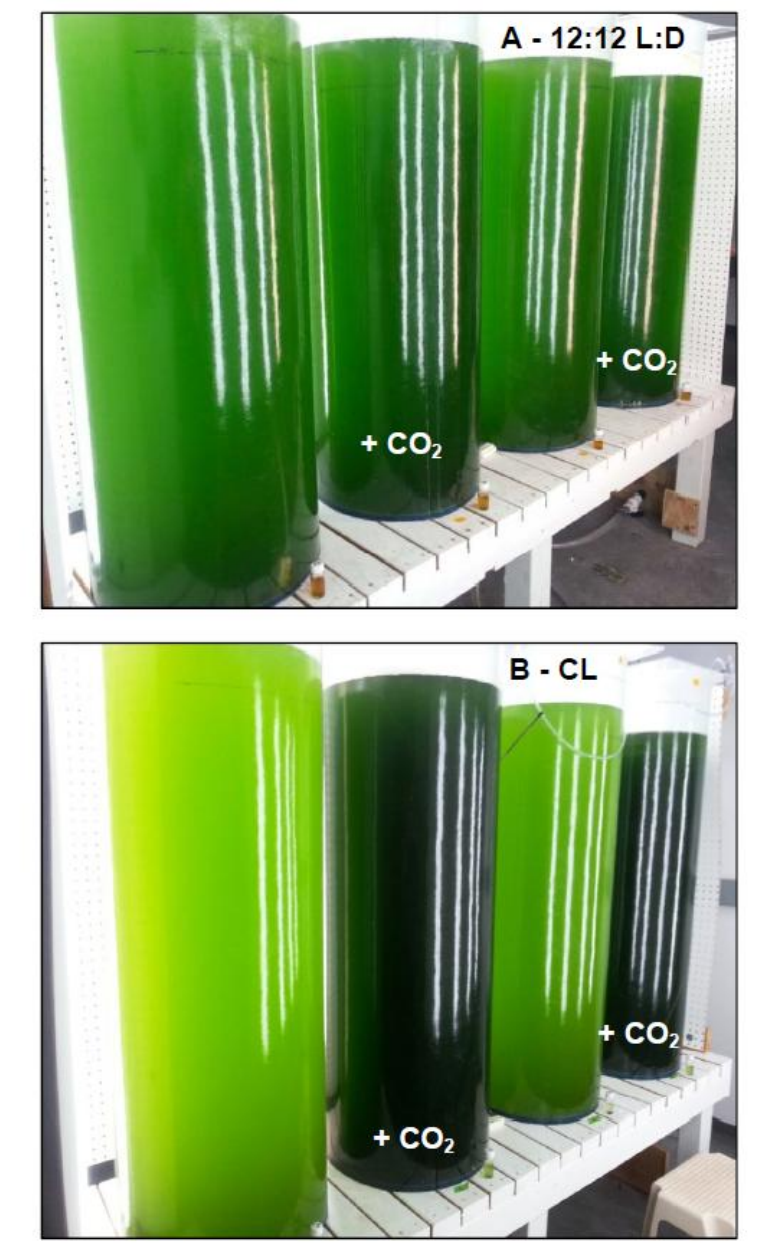

\author{
Figure
}




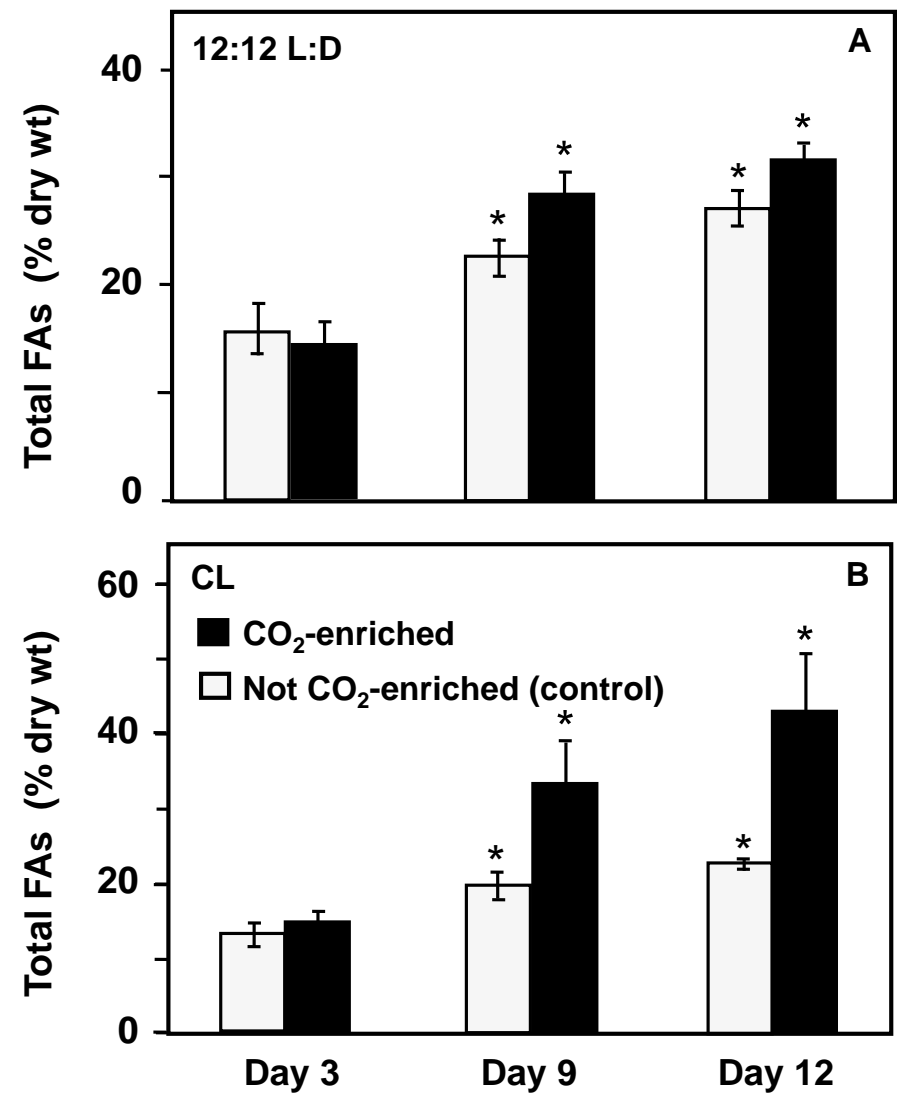




\begin{tabular}{|c|c|c|c|}
\hline Species Name * & $\begin{array}{c}\text { Commercial Source and } \\
\text { Strain Number }\end{array}$ & $\begin{array}{l}\text { Biovolume }\left(\mu \mathrm{m}^{3} \text {, mean }\right. \\
\quad \pm 1 \mathrm{SE}, \mathrm{n}=30)\end{array}$ & $\begin{array}{c}\text { Maximum Cell } \\
\text { Production }\left(10^{6} \text { cells }\right. \\
\qquad / \mathrm{mL} \pm 1 \mathrm{SE} ; \mathrm{n}=3) \\
\text { in } \mathrm{L} 1-\mathrm{Si} \text { medium }\end{array}$ \\
\hline Dunaliella tertiolecta & CCAP $19 / 9$ & $120 \pm 6$ & $6.2 \pm 0.9$ \\
\hline Dunaliella tertiolecta & CCAP 19/24 & $132 \pm 6$ & $3.4 \pm 0.4$ \\
\hline Dunaliella tertiolecta & UTEX 999 & $4.4 \pm 0.8$ & $4.4 \pm 0.8$ \\
\hline Dunaliella tertiolecta ${ }^{* *}$ & UTEX 1000 & $168 \pm 8$ & $6.6 \pm 0.8$ \\
\hline Dunaliella viridis & UTEX ZZ1150 & $10.0 \pm 0.6$ & $10.0 \pm 0.6$ \\
\hline
\end{tabular}

* We refer here to the $D$. tertiolecta strains by the species name indicated from our ITS2 sequence data, ; The $D$. viridis strain was a contaminant from a commercial culture, and was deposited by the NCSU Cente UTEX collection.

** This strain inexplicably stopped growth and lipid production, so its use in the study was discontinued. 


\begin{tabular}{ccc} 
Treatment & $\begin{array}{c}\text { pH after 10 days } \\
\text { under 12:12 L:D }\end{array}$ & $\begin{array}{c}\text { pH after } 3 \text { days } \\
\text { under CL }\end{array}$ \\
\hline Control & 9.39 & 9.43 \\
$\mathrm{~N}+\mathrm{P}$ & 9.2 & 9.45 \\
$\mathrm{P}$ & 9.38 & 9.55 \\
$\mathrm{~N}$ & 9.41 & 9.64 \\
\hline Treatment & pH after 10 days & pH after 3 days \\
& under 12:12 L:D & under CL \\
\hline Control & 9.25 & 9.43 \\
$\mathrm{~N}+\mathrm{P}$ & 8.43 & 8.99 \\
$\mathrm{P}$ & 8.70 & 9.24 \\
$\mathrm{~N}$ & 8.80 & 9.27 \\
\hline
\end{tabular}




\begin{tabular}{|c|c|c|c|c|}
\hline Treatment & Day & $\begin{array}{c}\text { Total FAs (\%) (mean } \\
\pm 1 \text { SE) }\end{array}$ & LS Mean Diff & $p$ value \\
\hline \multirow{5}{*}{ Salinity 60 to 30 (unadjusted) } & 3 & $9.6 \pm 1.7$ & & n.a. \\
\hline & 6 & $29.8 \pm 7.0$ & 20.19 & 0.003 \\
\hline & 9 & $28.6 \pm 8.0$ & 18.95 & 0.004 \\
\hline & 12 & $41.7 \pm 6.6$ & 32.09 & $<0.001$ \\
\hline & 14 & $39.8 \pm 4.6$ & 30.23 & $<0.001$ \\
\hline \multirow{4}{*}{ Salinity 60 to 30 (adjusted) } & 3 & $19.2 \pm 2.5$ & & n.a. \\
\hline & 6 & $33.8 \pm 7.6$ & 14.59 & n.s. \\
\hline & 9 & $55.6 \pm 3.1$ & 36.44 & 0.014 \\
\hline & 12 & $46.1 \pm 15.6$ & 26.86 & 0.031 \\
\hline \multirow{5}{*}{ Salinity 60 to 60 (unadjusted) } & 3 & $13.0 \pm 4.6$ & & n.a. \\
\hline & 6 & $18.4 \pm 5.9$ & 5.38 & n.s. \\
\hline & 9 & $23.7 \pm 3.6$ & 10.64 & 0.019 \\
\hline & 12 & $26.5 \pm 4.4$ & 13.49 & 0.007 \\
\hline & 14 & $37.7 \pm 1.2$ & 24.66 & $<0.001$ \\
\hline
\end{tabular}




\begin{tabular}{|c|c|c|c|c|c|}
\hline Strain & $\mathrm{pH}$ & Time Point & Mean \pm 1 SE (\%) & LS Mean Diff & $p$ value \\
\hline \multirow{14}{*}{ D. tertiolecta CCAP $19 / 9$} & 10 & Control & $14.5 \pm 1.7$ & & n.a. \\
\hline & & $30 \mathrm{sec}$ & $18.9 \pm 1.8$ & 4.44 & n.s \\
\hline & & $5 \min$ & $18.9 \pm 0.8$ & 4.40 & n.s. \\
\hline & & $30 \mathrm{~min}$ & $17.6 \pm 1.2$ & 3.09 & n.s. \\
\hline & & $1 \mathrm{hr}$ & $19.1 \pm 5.2$ & 4.61 & n.s. \\
\hline & & $2 \mathrm{hr}$ & $17.8 \pm 2.9$ & 2.86 & n.s. \\
\hline & & $24 \mathrm{hr}$ & $19.7 \pm 6.0$ & 5.25 & 0.046 \\
\hline & 7 & Control & $15.3 \pm 2.7$ & & n.a. \\
\hline & & $30 \mathrm{sec}$ & $19.6 \pm 3.3$ & 4.37 & 0.004 \\
\hline & & $5 \mathrm{~min}$ & $18.7 \pm 1.7$ & 3.41 & 0.015 \\
\hline & & $30 \mathrm{~min}$ & $19.6 \pm 2.4$ & 4.37 & 0.004 \\
\hline & & $1 \mathrm{hr}$ & $19.5 \pm 3.1$ & 4.23 & 0.005 \\
\hline & & $2 \mathrm{hr}$ & $20.5 \pm 2.3$ & 5.25 & 0.001 \\
\hline & & $24 \mathrm{hr}$ & $19.6 \pm 1.3$ & 4.35 & 0.004 \\
\hline \multirow{14}{*}{ D. tertiolecta CCAP $19 / 9$} & 10 & Control & $30.2 \pm 3.6$ & & n.a. \\
\hline & & $30 \mathrm{sec}$ & $28.0 \pm 1.4$ & -2.18 & 0.049 \\
\hline & & $5 \mathrm{~min}$ & $30.3 \pm 0.7$ & 0.11 & n.s. \\
\hline & & $30 \mathrm{~min}$ & $28.4 \pm 3.8$ & -1.76 & n.s. \\
\hline & & $1 \mathrm{hr}$ & $25.0 \pm 0.9$ & -5.23 & 0.001 \\
\hline & & $2 \mathrm{hr}$ & $29.5 \pm 1.7$ & -0.24 & n.s. \\
\hline & & $24 \mathrm{hr}$ & $26.9 \pm 1.2$ & -3.25 & 0.01 \\
\hline & 7 & Control & $30.8 \pm 1.1$ & & n.a. \\
\hline & & $30 \mathrm{sec}$ & $35.6 \pm 1.9$ & 4.82 & 0.081 \\
\hline & & $5 \mathrm{~min}$ & $32.0 \pm 2.5$ & 1.19 & n.s. \\
\hline & & $30 \mathrm{~min}$ & $32.5 \pm 12.8$ & 1.69 & n.s. \\
\hline & & $1 \mathrm{hr}$ & $30.8 \pm 4.3$ & 0.02 & n.s. \\
\hline & & $2 \mathrm{hr}$ & $29.6 \pm 0.6$ & -1.18 & n.s. \\
\hline & & $24 \mathrm{hr}$ & $29.9 \pm 4.8$ & -0.90 & n.s. \\
\hline \multirow{8}{*}{ D. tertiolecta UTEX 999} & 10 & Control & $18.7 \pm 2.6$ & & n.a. \\
\hline & & $30 \mathrm{sec}$ & $23.9 \pm 2.1$ & 5.22 & 0.006 \\
\hline & & $5 \min$ & $22.5 \pm 4.2$ & 3.83 & 0.025 \\
\hline & & $30 \mathrm{~min}$ & $19.9 \pm 2.9$ & 1.26 & n.s. \\
\hline & & $1 \mathrm{hr}$ & $20.1 \pm 4.3$ & 1.40 & n.s. \\
\hline & & $2 \mathrm{hr}$ & $21.7 \pm 3.6$ & 3.08 & n.s. \\
\hline & & $24 \mathrm{hr}$ & $22.2 \pm 1.6$ & 3.50 & 0.035 \\
\hline & 7 & Control & $21.3 \pm 5.0$ & & n.a. \\
\hline
\end{tabular}




\begin{tabular}{|c|c|c|c|c|}
\hline Method & Day & $\begin{array}{l}\text { Total FAs (mean } \\
\quad \pm 1 \mathrm{SE}, \% \text { ) }\end{array}$ & LS Mean Diff & $p$ value \\
\hline \multirow{3}{*}{$12: 12$, no $\mathrm{CO}_{2}$} & 6 & $15.8 \pm 2.3$ & & n.a. \\
\hline & 9 & $22.8 \pm 1.3$ & 7.01 & 0.003 \\
\hline & 12 & $27.2 \pm 1.8$ & 11.36 & $<0.001$ \\
\hline \multirow{3}{*}{$12: 12$, no $\mathrm{CO}_{2}$} & 6 & $14.3 \pm 2.9$ & & n.a. \\
\hline & 9 & $27.9 \pm 2.5$ & 13.59 & $<0.001$ \\
\hline & 12 & $31.5 \pm 1.8$ & 17.20 & $<0.001$ \\
\hline \multirow{3}{*}{$\mathrm{CL}, \mathrm{no} \mathrm{CO}_{2}$} & 6 & $13.0 \pm 1.6$ & & n.a. \\
\hline & 9 & $19.6 \pm 2.2$ & 6.52 & 0.001 \\
\hline & 12 & $22.6 \pm 1.2$ & 9.58 & $<0.001$ \\
\hline \multirow{3}{*}{$\mathrm{CL}$ with $\mathrm{CO}_{2}$} & 6 & $14.2 \pm 1.5$ & & n.a. \\
\hline & 9 & $33.2 \pm 5.9$ & 19.07 & 0.011 \\
\hline & 12 & $42.8 \pm 8.2$ & 28.67 & 0.002 \\
\hline
\end{tabular}


Day

Comparison

\begin{tabular}{|c|c|c|c|c|c|c|}
\hline \multirow[t]{4}{*}{9} & $12: 12$, no CO$_{2}$ & vs. & $12: 12$ with $\mathrm{CO}_{2}$ & 22.8 & 27.9 & -6.58 \\
\hline & $\mathrm{CL}$, no $\mathrm{CO}_{2}$ & vs. & $\mathrm{CL}$ with $\mathrm{CO}_{2}$ & 19.6 & 33.2 & -12.50 \\
\hline & $12: 12$, no $_{2}$ & vs. & $\mathrm{CL}, \mathrm{no} \mathrm{CO}_{2}$ & 22.8 & 19.6 & 0.49 \\
\hline & $12: 12$, with $\mathrm{CO}_{2}$ & vs. & $\mathrm{CL}$ with $\mathrm{CO}_{2}$ & 27.9 & 33.2 & - 5.48 \\
\hline \multirow[t]{4}{*}{12} & $12: 12$, no $\mathrm{CO}_{2}$ & vs. & $12: 12$ with $\mathrm{CO}_{2}$ & 27.2 & 31.5 & -5.84 \\
\hline & $\mathrm{CL}$, no $\mathrm{CO}_{2}$ & vs. & $\mathrm{CL}$ with $\mathrm{CO}_{2}$ & 22.6 & 42.8 & -19.10 \\
\hline & $12: 12$, no CO$_{2}$ & vs. & $\mathrm{CL}$, no $\mathrm{CO}_{2}$ & 27.2 & 22.6 & 1.79 \\
\hline & $12: 12$ with $\mathrm{CO}_{2}$ & vs. & $\mathrm{CL}$ with $\mathrm{CO}_{2}$ & 31.5 & 42.8 & -11.50 \\
\hline \multirow[t]{2}{*}{12} & $12: 12$ & vs. & $\mathrm{CL}$ & 29.3 & 32.7 & -9.67 \\
\hline & no $\mathrm{CO}_{2}$ & vs. & with $\mathrm{CO}_{2}$ & 24.9 & 37.2 & -24.90 \\
\hline
\end{tabular}

Total FAs (\%) (means) LS Mean Diff 